\title{
Alternative modeling of multiply hydraulic fractures in horizontal wells Completed in low permeability formation
}

\author{
Mahmod S. Alkalawi \\ West Virginia University
}

Follow this and additional works at: https://researchrepository.wvu.edu/etd

\section{Recommended Citation}

Alkalawi, Mahmod S., "Alternative modeling of multiply hydraulic fractures in horizontal wells Completed in low permeability formation" (2011). Graduate Theses, Dissertations, and Problem Reports. 2290. https://researchrepository.wvu.edu/etd/2290

This Thesis is protected by copyright and/or related rights. It has been brought to you by the The Research Repository @ WVU with permission from the rights-holder(s). You are free to use this Thesis in any way that is permitted by the copyright and related rights legislation that applies to your use. For other uses you must obtain permission from the rights-holder(s) directly, unless additional rights are indicated by a Creative Commons license in the record and/ or on the work itself. This Thesis has been accepted for inclusion in WVU Graduate Theses, Dissertations, and Problem Reports collection by an authorized administrator of The Research Repository @ WVU. For more information, please contact researchrepository@mail.wvu.edu. 
Alternative modeling of multiply hydraulic fractures in horizontal wells Completed in low permeability formation

Mahmod S. Alkalawi

Thesis submitted to the College of Engineering and Mineral Resources

at West Virginia University in partial fulfillment of the requirements

for the degree of

Master of Science

in

Petroleum and Natural Gas Engineering

Kashy Aminian, Ph.D. Chair

Sam Ameri, M.S.

Daniel E. Della-Giustina, Ph.D.

Department of Petroleum and Natural Gas Engineering

Morgantown, West Virginia

2011

Keywords: Unconventional gas reservoir, Fracture modeling, Horizontal wells, Total Gas Production, Hydraulic Fracturing (Longitudinal and transverse fracture). 


\begin{abstract}
Alternative modeling of multiply hydraulic fractures in horizontal wells completed in low permeability formations
\end{abstract}

\begin{abstract}
Mahmod S. Alkalawi
Many conventional gas reservoirs around the world have been developed and well-understood on contrary to unconventional gas reservoirs where the amount of information available to the public considered still not abundant. The unconventional reservoirs (tight formation) where permeability ranges from 0.001 millidarciesto micro-Darcy permeability is a relatively new area in some parts of the world and the details involving ways to increase productivity of wells and best fracture design yet has to be investigated .The unconventional gas reservoirs are important in the world due to its availability, future energy demand around the world, and most conventional gas reservoirs have already been utilized and exploited and its reserves are in decline. Through reservoir simulation, the tight gas formation could be studied to find the effects of these parameters on gas production. The objective of this research is to find the alternative modeling of multiply hydraulic fractures in horizontal wells completed in low permeability formation. Parameters include, Propped fracture half-length for both (longitudinal or transverse fracture), number of fractures and outermost fracture distance in the multiply fractures system.
\end{abstract}




\section{Acknowledgements}

I would like to express my grateful thanks to Dr. Kashy Aminian first for being my academic advisor. His experience in oil and gas industry, commitment, patience with me, encouragement throughout finishing this research, guidance and explanations has made this research come to existence.

Next, my thanks go also to the other committee members. First, Professor Sam Ameri, I would like to thank you for everything you have done to me since the first time I met you in the Oil and Natural Gas Engineering Department. I really appreciate your experience, knowledge and respect that you taught me during my period of study. I would also like to really thank Dr.Daniel E. Della-Giustina for your support, assistance and accepting to serve on my in the committee. Thanks, also goes to the rest of the faculty and staff in the Department of Petroleum and Natural Gas Engineering at West Virginia University.

Lastly, I can’t go on any further without thanking my parents, Fatima and Souliman. No matter what, they have always been there for me my entire life. I can't thank them enough for everything that they have done for me. My deepest appreciation goes to them. Also, I would like to thank the rest of my family, brothers and sisters for their effort and encouragement that they have shown to me during my period of study.

Finally, I have not forgotten my wife! I would like to dedicate my thesis to my dear wife, Galya Youniss. Thank you for your help, support and endless motivation through entire my study. 


\section{Table of Contents}

Contents $\quad$ Page

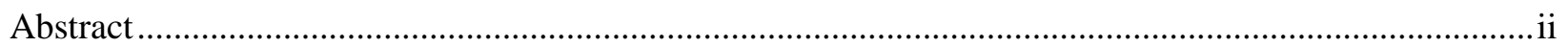

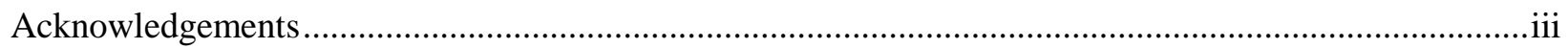

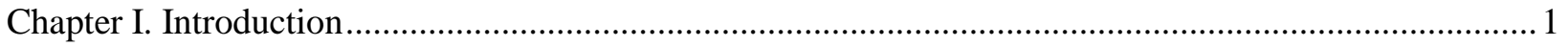

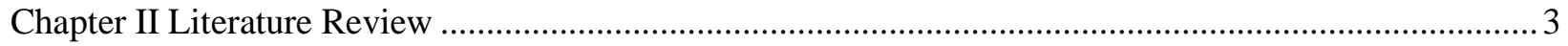

2.1. Definition of an Unconventional Gas Reservoir ........................................................................... 3

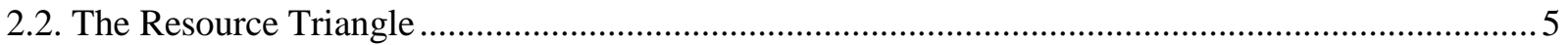

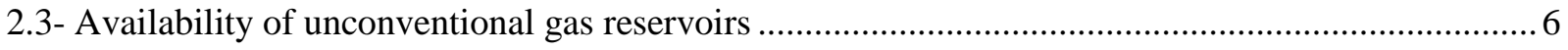

2.4- Role of Natural gas in the United Stats' energy portfolio .......................................................... 7

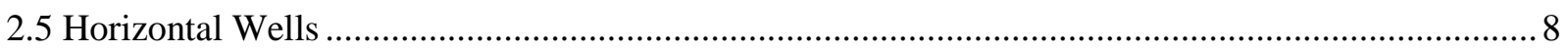

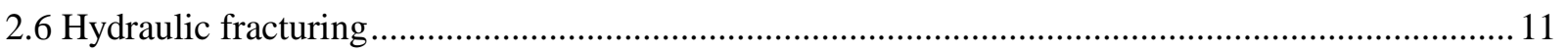

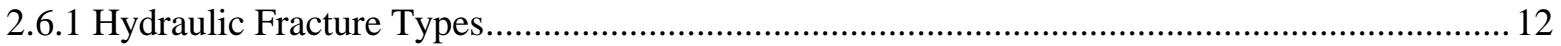

2.6.2 Dimensionless Fracture Conductivity (FCD) ....................................................................... 13

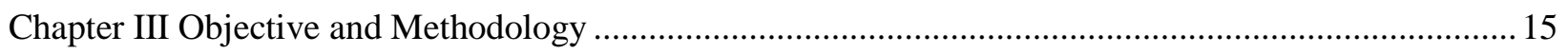

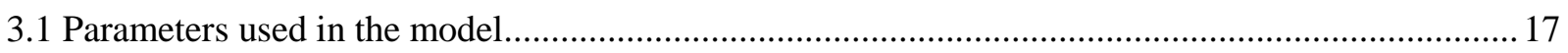

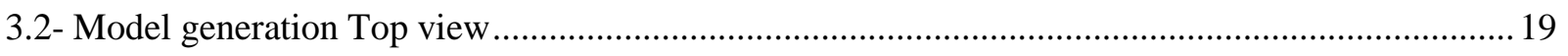

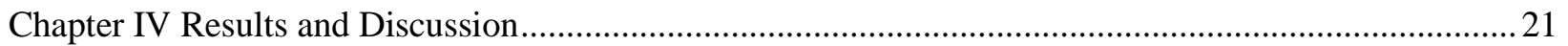

4.1 Multiply fractures of $300 \mathrm{ft}$ fracture half length with effective longitudinal fracture.....................2 21

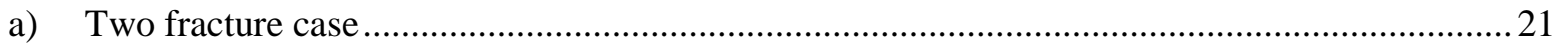

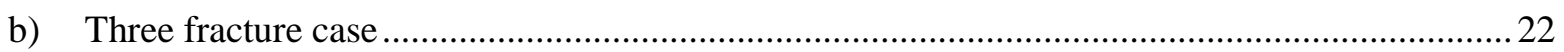

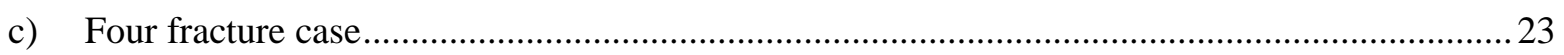

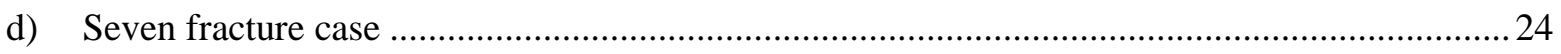

4.2 Multiply fractures of $400 \mathrm{ft}$ fracture half length with effective longitudinal fracture .....................25

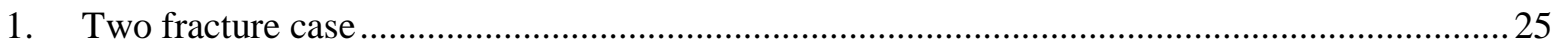

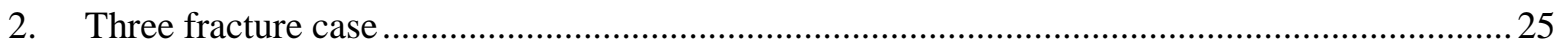

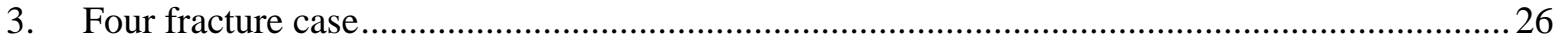

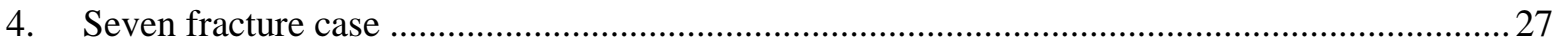


Chapter V. Conclusions\&Recommendations

NOMENCLATURE

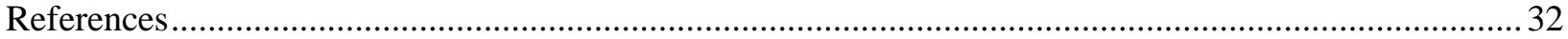

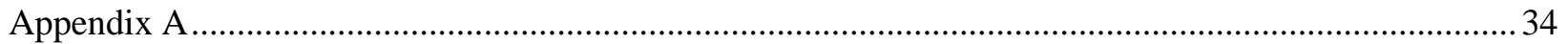


List of Tables

Page

Table II- 1 Distribution of worldwide unconventional gas reservoirs ${ }^{(5)}$................................................ 6

Table III- 1 reservoir data used in the model ..................................................................................... 17

Table III- 2 Fracture Parameters used in the model ............................................................................. 18

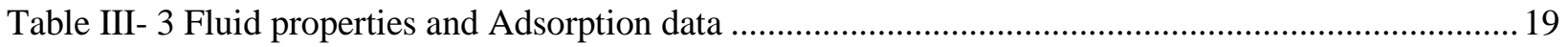

Table IV -1 summary results of multiply fractured (xf=300ft) horizontal well and effective longitudinal

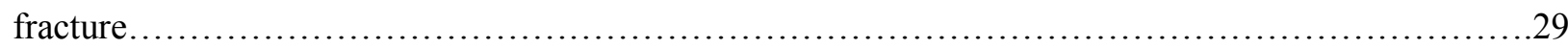

Table IV-2 summary results of multiply fractured $(\mathrm{xf}=400 \mathrm{ft})$ horizontal well and effective longitudinal

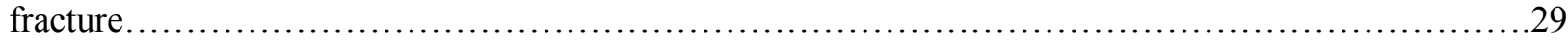




\section{List of Figures}

Figure II- 1 . a thin section of a conventional sandstone reservoir that has been injected with blue epoxy. The blue areas are pore space and would contain natural gas in a producing gas field. The pore space can be seen to be interconnected so gas is able to flow easily from the rock. (G.C. Naik, Tight Gas ReservoirsAn Unconventional Natural Energy Source for the Future)

Figure II- 2 Thin section Photo of a tight gas sandstone. The blue areas are pores. The pores are irregularly distributed through the reservoir and the porosity of the rock can be seen to be much less than the conventional reservoir. (G. C. Naik, Tight Gas Reservoir- An Unconventional Natural Energy Source

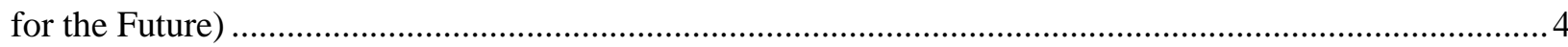

Figure II- 3. The resource triangle for oil and gas reservoirs (Lane, 1989) ….........................................5

Figure II- 4 shows natural gas production by source (Tcf/year)........................................................... 7

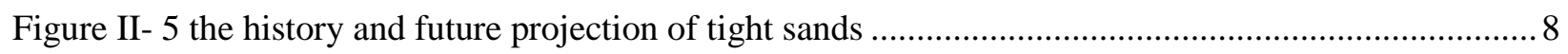

Figure II- 6 Applications for horizontal wells (G. C Thakur, Chevron PTC) ............................................

Figure II- 7 Greater Length of Producing Formation Exposed to the Wellbore in a Horizontal Well (A)

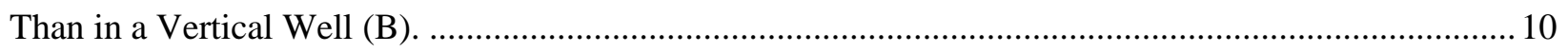

Figure II- 8 Flushing fractured horizontal well with proppant ........................................................... 12

Figure II-9 shows both transverse fractures (A) and longitudinal fracture (B) in a horizontal well........13

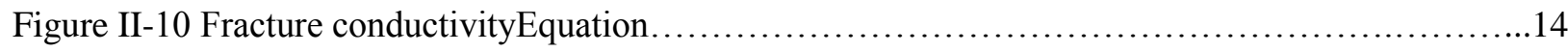

Figure II-11 Infinite-conductivity and finite-conductivity fractures................................. 14

Figure III-12 Multiply-fractured-horizon-well in a tight formation and the effective (total) fracture

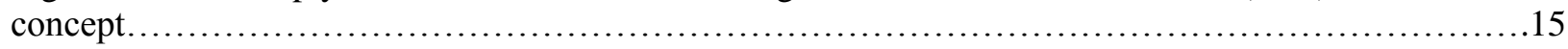

Figure III-13 Top view of the model with three multiply fractures..............................20

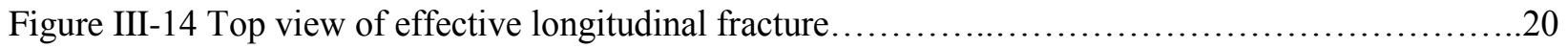

Figure IV - 1 two fractures vs. effective longitudinal fracture ............................................................... 22

Figure IV - 2 three fractures vs. effective longitudinal fracture ...........................................................22

Figure IV - 3 four fractures vs. effective longitudinal fracture ..............................................................23

Figure IV- 4 seven fractures vs. effective longitudinal fracture ............................................................24

Figure IV - 5 two fractures vs. effective longitudinal fracture ............................................................. 25

Figure IV - 6 three fractures vs. effective longitudinal fracture ...........................................................26

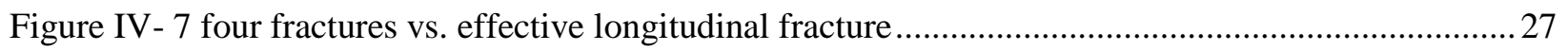


Figure IV- 8 seven fractures vs. effective longitudinal fracture (reservoir dimensions $=4000 \mathrm{ft}$ by $1000 \mathrm{ft}$ )

Figure IV- 9 seven fractures vs. effective longitudinal fracture (reservoir dimensions $=4000 \mathrm{ft}$ by

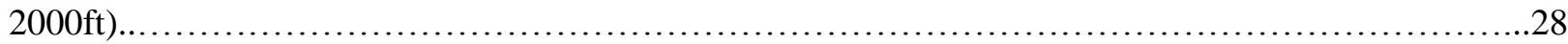

Figure A- 1 Schlumberger's Eclipse software main window ................................................................. 34

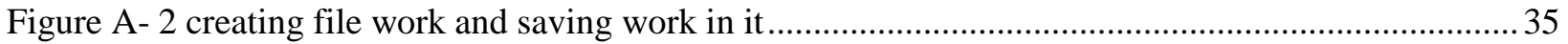

Figure A- 3 window shows simulation run period for gas production and main model options ................ 35

Figure A- 4 reservoir description window (Layers option) ..................................................................... 36

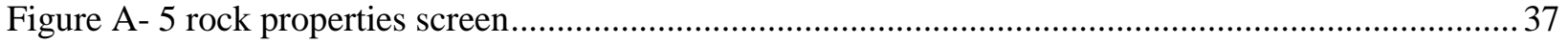

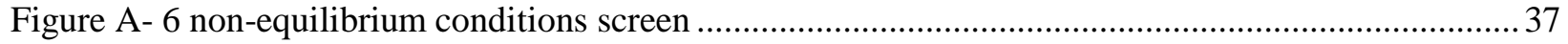

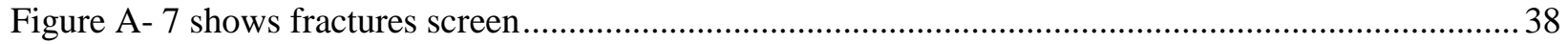

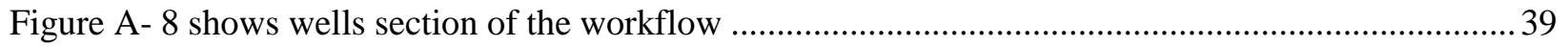

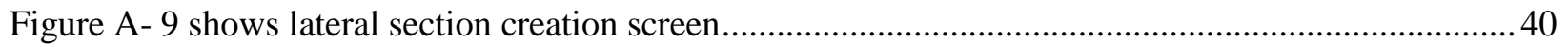

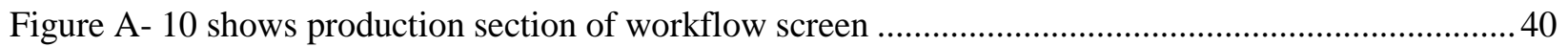

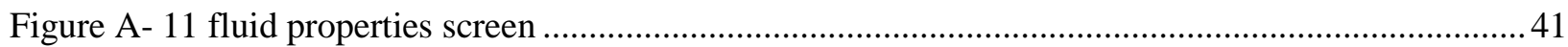

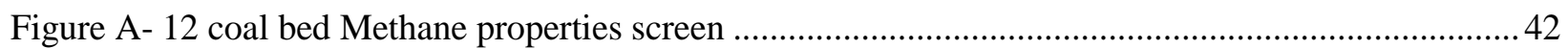

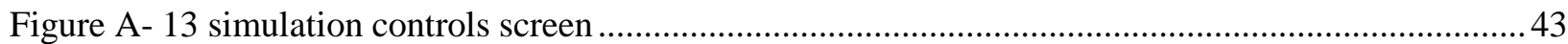

Figure A- 14 generated model of horizontal well with three multiply fractures...................................... 44

Figure A- 15 generated model in case of effective longitudinal fracture ...............................................45

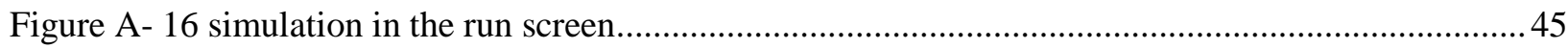

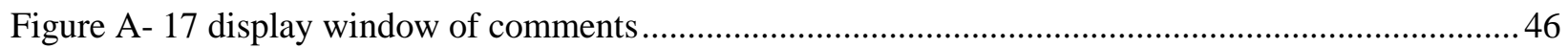

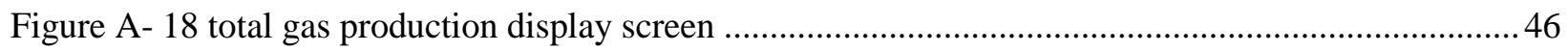

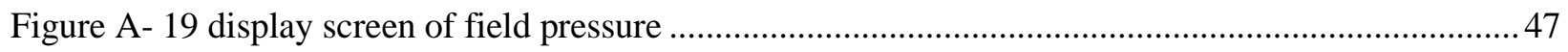

Figure A- 20 shows pressure distribution in and around fractures after 20 years of gas production.......... 48 


\section{Chapter I. Introduction}

Natural gas can be produced from both conventional and unconventional gas reservoirs. Even though conventional gas reservoirs are considered easily to exploit worldwide, their gas reserves are declining due to high demand for energy in North America. Unconventional gas reservoirs were the solution in developed countries such as the United States, where the demand for natural gas is high. However, a lot of scientific information is needed to be collected about them.

Unconventional gas reservoirs are defined by their low permeability, ranging from 0.001 millidarcies to micro-Darcy. Unconventional Gas formations are hard to produce unless the reservoir stimulated using hydraulic fracturing. Unconventional natural gas production in North America has increased nearly $65 \%$, from 5.4 Tcf/year in1998 to 8.9 Tcf/year in $2007^{(1)}$. Therefore, the future in the gas industry is unconventional gas. Overall, unconventional gas resources are anticipated to become an ever increasing portion of the US proven reserves, building the bulk of the USA natural gas supply for the next 20 years, while production from conventional gas reservoirs will be declining ${ }^{(2)}$.

With advanced drilling technology in hand, not only vertical wells can be used to develop tight gas reservoirs, but horizontal drilling wells are highly effective in terms of gas productivity. Therefore, the horizontal wells applications have grown rapidly over the past decade in the world especially in the United States of America.

Hydraulic fracturing is an important technology to obtain production from the low permeability formations. Hence, it is commonly utilized to stimulate the production of oil and 
natural gas. Horizontal well with hydraulic fractures are making a significant impact in what was once considered unproductive unconventional gas formations into the largest economic natural gas deposits in the world.

The Eclipse Schlumberger software simulator has been used in this study to simulate the gas production from the low permeability gas formation. In addition, applying both horizontal well and hydraulic fractures (transverse and longitudinal fractures) to measure the total gas produced from both types of hydraulic fracturing. 


\section{Chapter II. Literature Review}

\subsection{Definition of an Unconventional Gas Reservoir}

According to the United States governments, unconventional gas reservoirs are reservoirs whose permeability would be less than $0.1 \mathrm{md}$. The above definition was a political one for the USA government to determine which wells would need federal or state tax credits, in order to produce gas from low permeability formations which included; tight sand, coal-bed methane, and shale.

Actually, the industry accepted definition for unconventional gas reservoirs is affected by economic factors and physical ones, which can be explained by Darcy's Law as follows:

$$
\mathrm{q}=\frac{\mathrm{kh}(\mathrm{Pr}-\mathrm{Pwf})}{141.2 \overline{\mathrm{B}} \bar{\mu}\left[\ln \left(\frac{\mathrm{re}}{\mathrm{rw}}\right)-0.75+\mathrm{s}\right]}
$$

The above equation clearly explains the flow rate, q, is a function of reservoir permeability $\mathrm{k}$; net pay thickness of the reservoir; average reservoir pressure $\overline{\mathrm{p}}$; flowing pressurePwf, formation volume factor and gas viscosity calculated at the average pressure of the reservoir, $\bar{B} \bar{\mu}$; drainage area re; wellbore radiusrw; and formation skin factor s.Hence, to choose a single value of permeability to define "tight gas or unconventional gas" is of limited importance. As an example, in deep, high-pressure, thick reservoirs, commercial completions can be satisfied with the permeability of gas in micro-darcy range. In shallow, low-pressure, thin reservoirs, economic gas flow rates can be achieved with formation permeability of millidarcies, even after a successful fracture treatment. As a result, an unconventional gas reservoir can be found in deep or shallow formation; high pressure or low pressure and thin or thick reservoir. 
Some petroleum engineers summarize unconventional gas reservoirs by; reservoirs that cannot be productive economically without stimulation treatment. By utilizing hydraulic fracturing and horizontal wells, it will be necessary to improve the reservoir poor permeability and well-bore contact with the reservoir, Based on this, the productivity. Figure II-1 and Figure II-2 show the differences between conventional reservoir permeability and unconventional reservoir permeability.

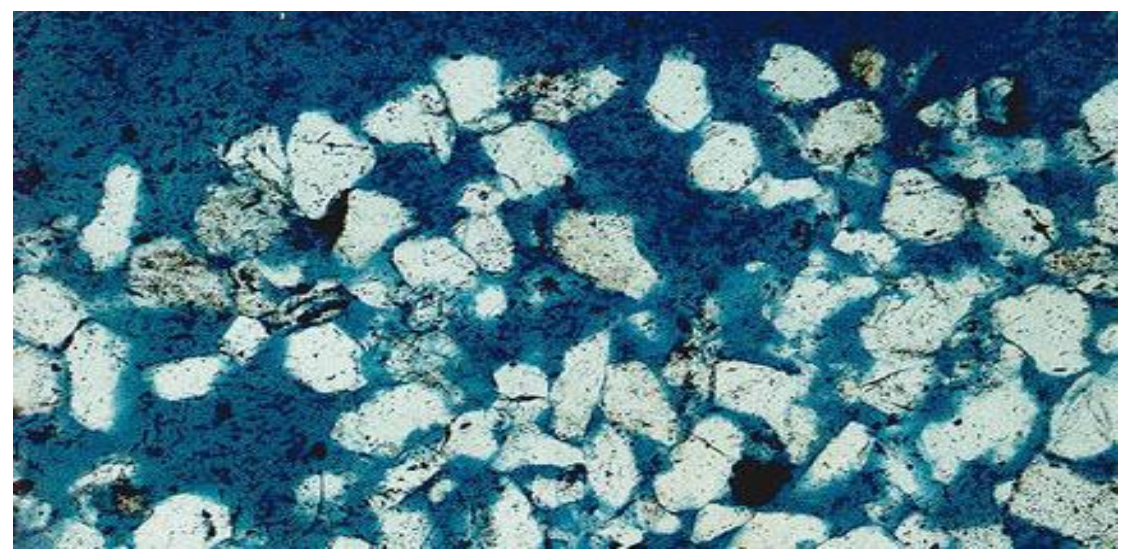

Figure II- 1 a thin section of a conventional sandstone reservoir that has been injected with blue epoxy. The blue areas are pore space and would contain natural gas in a producing gas field. The pore space can be seen to be interconnected so gas is able to flow easily from the rock. (G.C. Naik, Tight Gas Reservoirs- An Unconventional Natural Energy Source for the Future)

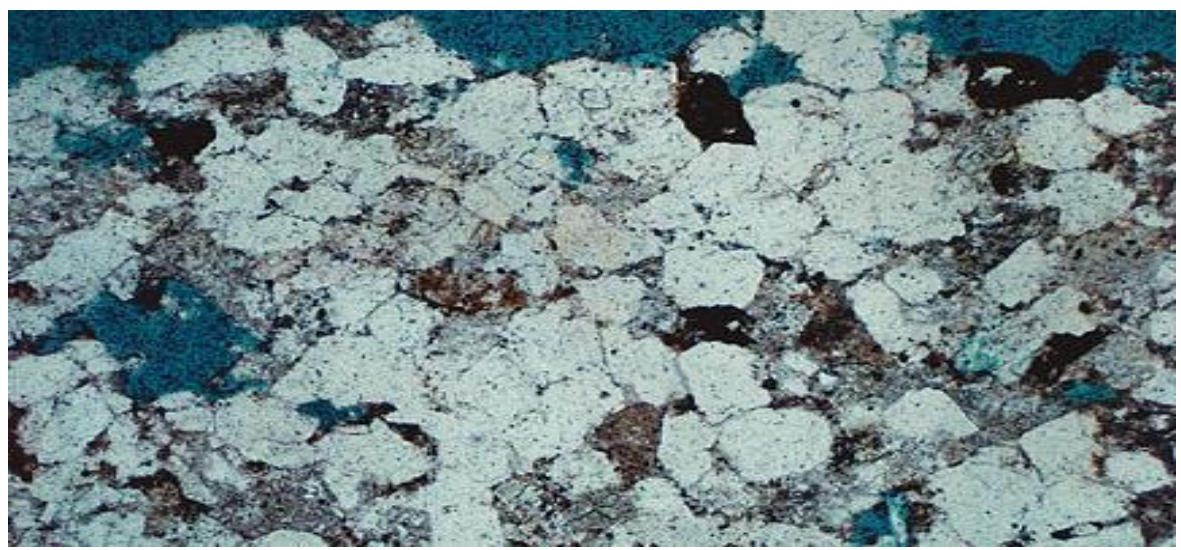

Figure II- 2 Thin section Photo of a tight gas sandstone. The blue areas are pores. The pores are irregularly distributed through the reservoir and the porosity of the rock can be seen to be much less than the conventional reservoir. (G. $C$. Naik, Tight Gas Reservoir- An Unconventional Natural Energy Source for the Future) 
Poor reservoir permeability is primarily caused by fine-grained nature of the sediments, overburden pressure, or infilling of pore spaces by carbonate or silicate cements settled down from water within the reservoir, therefore, blocks the pores in the reservoir.

\subsection{The Resource Triangle}

The resource triangle concept is helpful in understanding the distribution of gas reservoirs and the factors that aff ect them was used by Masters and Gray in the 1970s ${ }^{(3)}$. Figure II-3 illustrates the principles of the resource triangle. Conventional reservoirs are usually small and hard to find, yet easy to develop. Unconventional reservoirs are much larger and worldwide available, yet difficult to develop (Lane 1989). Unconventional reservoirs need high technology and are much more costly to develop. Due to gas demand and increasing in gas prices, the unconventional gas reservoirs can be developed and increase production.

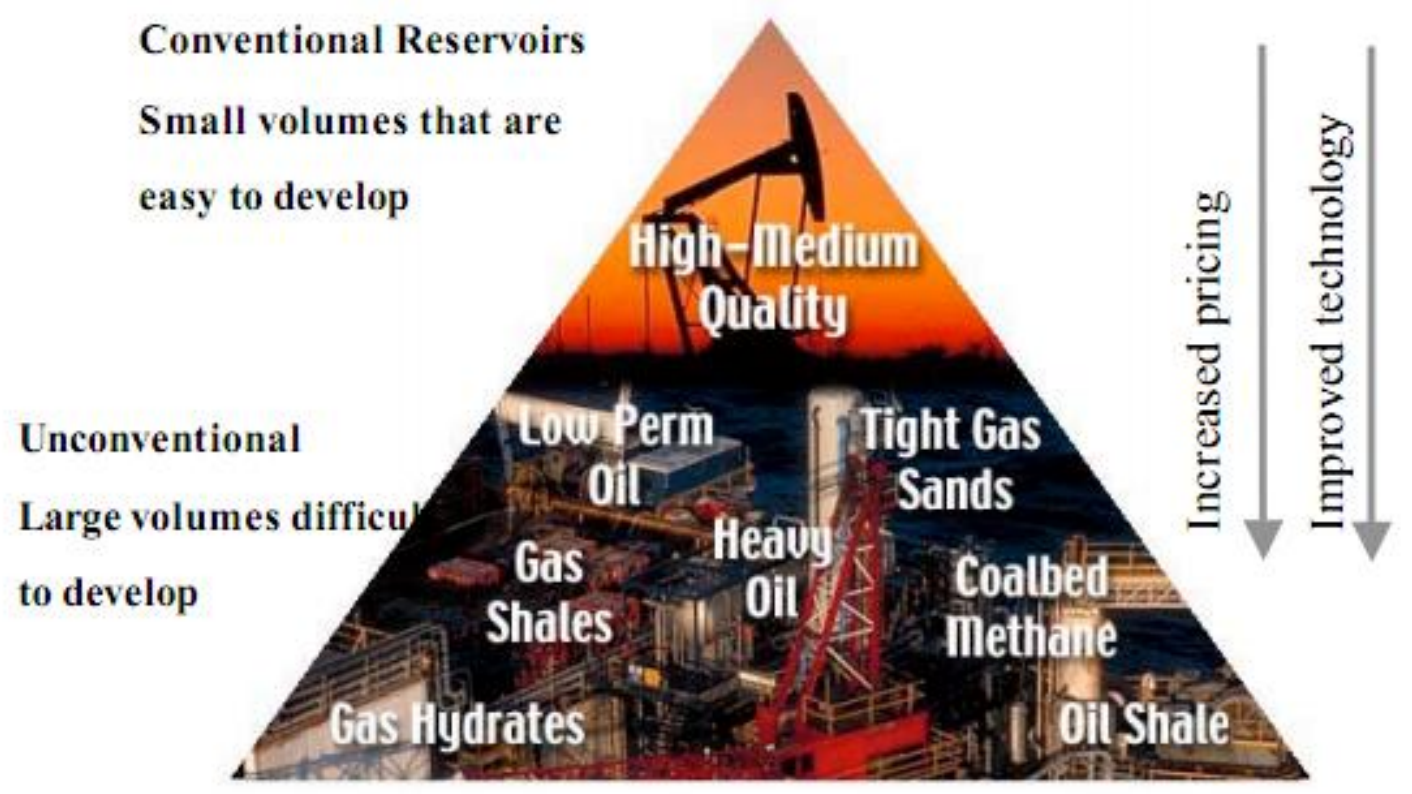

Figure II- 3. The resource triangle for oil and gas reservoirs (Lane, 1989) 


\section{3- Availability of unconventional gas reservoirs}

In the United States of America, unconventional gas reservoirs have received an increasing attention due to increasing demand for energy supply. However, around the world, unconventional gas reservoirs have not yet received close attention from natural gas operators. Moreover, the political conditions and gas market prices have not been helpful for development in many countries. In table II-1 below, Kawata and Fujita summarized the work of Ronger, who estimated the worldwide unconventional gas resources ${ }^{(4)}$.

Table II- 1 Distribution of worldwide unconventional gas reservoirs ${ }^{(5)}$

\begin{tabular}{|l|c|c|c|c|}
\hline Region & $\begin{array}{c}\text { Coal-bed } \\
\text { Methane } \\
\text { (Tcf) }\end{array}$ & $\begin{array}{c}\text { Shale Gas } \\
\text { (Tcf) }\end{array}$ & $\begin{array}{c}\text { Tight-Sand Gas } \\
\text { (Tcf) }\end{array}$ & Total (Tcf) \\
\hline North America & 3,017 & 3,842 & 1,371 & 8,228 \\
\hline Latin America & 39 & 2,117 & 1,293 & 3,448 \\
\hline Western Europe & 157 & 510 & 353 & 1,019 \\
\hline Central and Eastern Europe & 118 & 39 & 78 & 235 \\
\hline Former Soviet Union & 3,957 & 627 & 901 & 5,485 \\
\hline Middle East and North Africa & 0 & 2,548 & 823 & 3,370 \\
\hline Sub-Sahara Africa & 39 & 274 & 784 & 1,097 \\
\hline Centrally planned Asia and China & 1,215 & 3,528 & 353 & 5,094 \\
\hline $\begin{array}{l}\text { Pacific( Organization for Economic } \\
\text { Cooperation and Development) }\end{array}$ & 470 & 2,313 & 705 & 3,487 \\
& & & & 862 \\
\hline Other Asia Pacific & 0 & 314 & 549 & 235 \\
\hline South Asia & 39 & 0 & 196 & 32,560 \\
\hline World & 9,051 & 16112 & 7,406 & \\
\hline
\end{tabular}




\section{4- Role of Natural gas in the United Stats' energy portfolio}

Natural gas has an effective role in satisfying U.S. energy demands. Natural gas, coal and oil supply about 85 percent of the nation's energy, with natural gas supplying about 22 percent of the total ${ }^{(7)}$. Figure II-4. Shows natural gas production by source (Tcf/year).As clearly seen from the figure below; onshore unconventional gas supply increases with time due to the fact that with time the technology for development becomes more accessible for gas operators. Additionally, onshore conventional gas production declines with time.

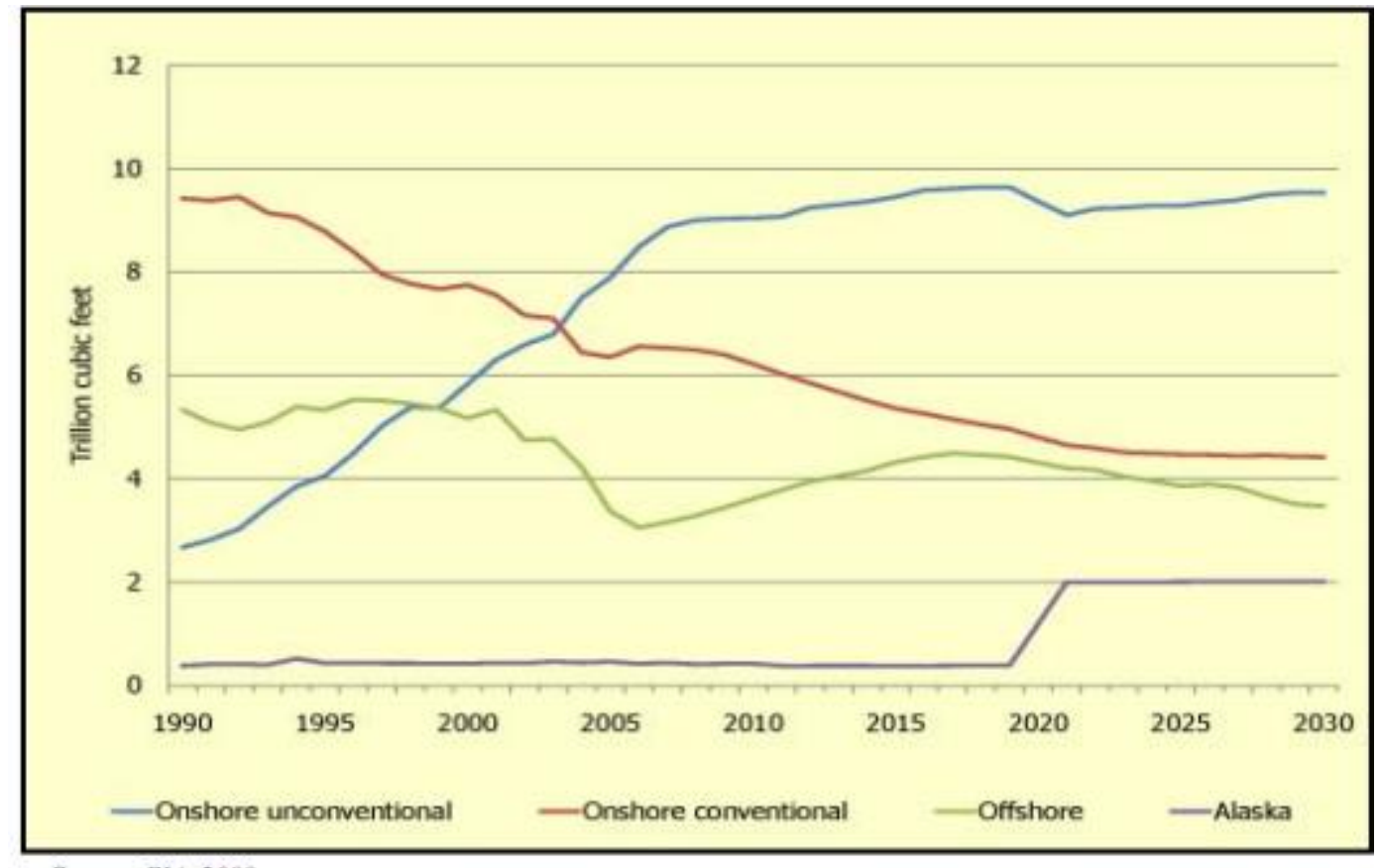

Source: ELA, 2008

Figure II- 4 shows natural gas production by source (Tcf/year) (Source: EIA, 2008)

The history and future projection of tight sands, coal-bed methane, and gas shale's (all considered unconventional gas sources) production is shown in Figure II-5below. While tight 
sands and gas shale's production generally tend to increase with time, coal bed methane tends to stay level with time.

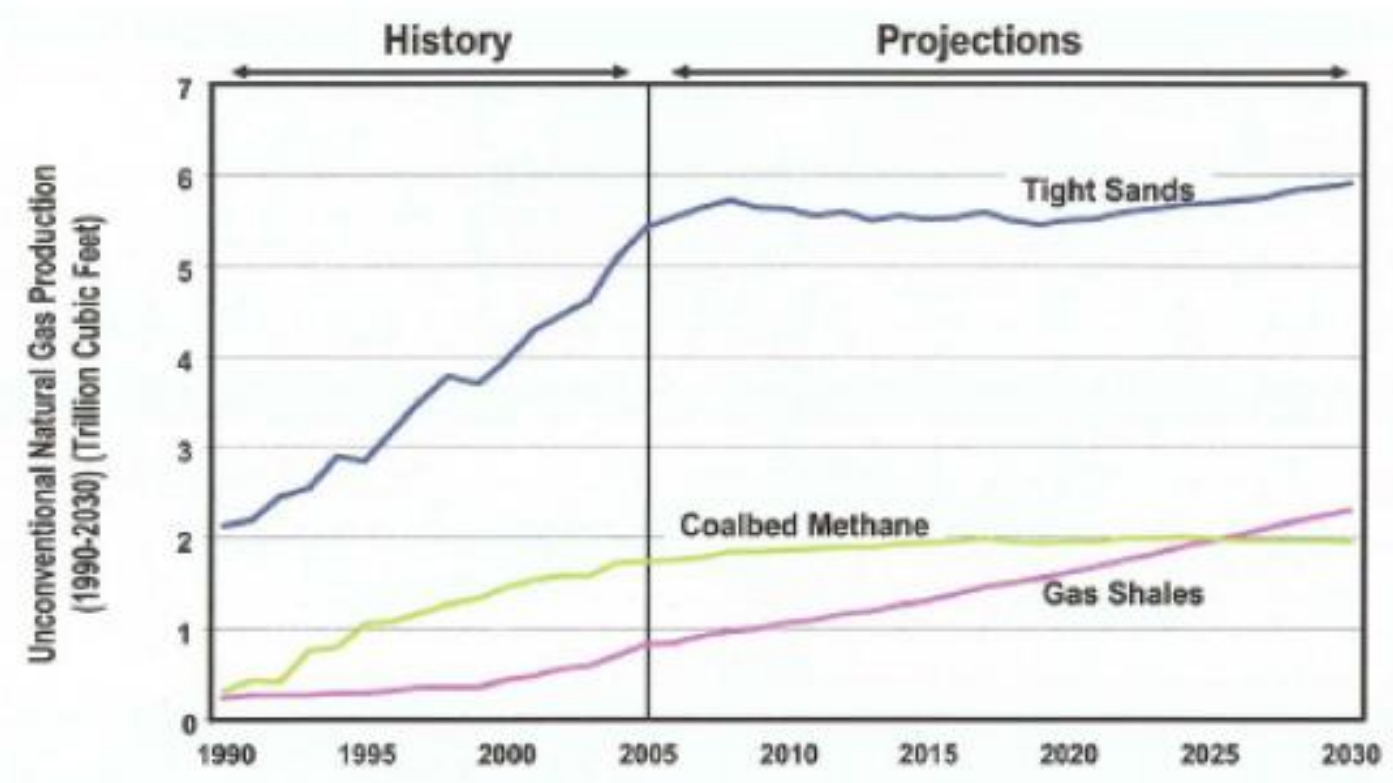

Source: ELA AEO 2007

Figure II- 5 the history and future projection of tight sands (Source: EIA AEO 2007)

\subsection{Horizontal Wells}

With improvements in horizontal well drilling, unconventional reservoirs have become the target of exploitation and its effectiveness in increasing productivity. Today, horizontal well technology is applied more often and in many different types of formations. The state of the art applications of horizontal well technology require better completion designs to optimize production rates, long-term economics, and ultimate producible reserves. Figure II-6 shows the variety of applications of horizontal wells. The technical objectives of horizontal wells are summarized below:

1. Expose significantly more reservoir rock to the well-bore than can be achieved by drilling of a conventional vertical well. Therefore, production rates increases and larger drainage 
areas can be exploited. Figure II-7 shows horizontal and vertical well differences in wellbore contact area.

2. Intersect natural fractures systems within a reservoir to increase the productivity of the reservoir.

3. The need to avoid unnecessarily premature water that would interfere with oil production.

4. Lower fluid velocities and reduced pressure drop around wellbore.

5. Reduced operating expenses because fewer wells may be required and, hence, minimal surface disturbance will be created.
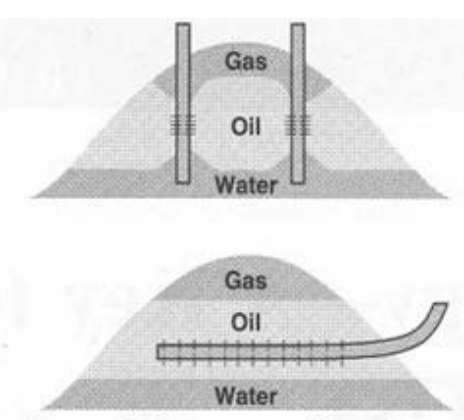

Reduce Water and/or Gas Coning

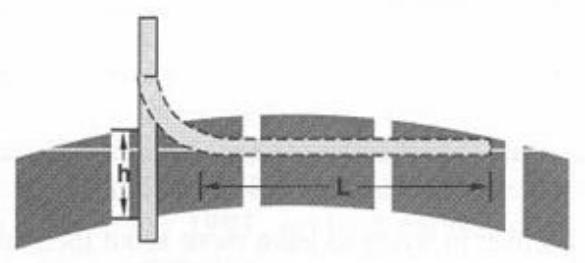

Exploit Thin Oil or Gas Zones
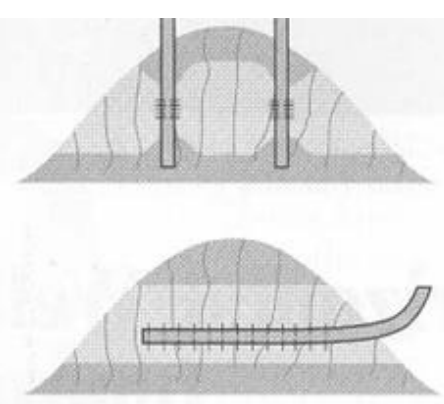

\section{Intersect Natural Fractures}

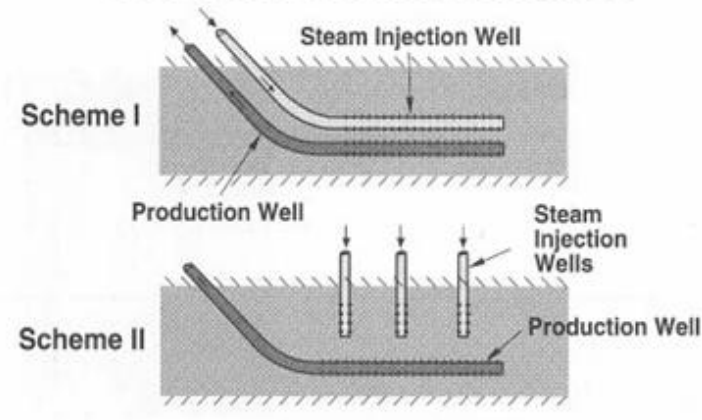

Enhance Heavy Oil Recovery

Figure II- 6 Applications for horizontal wells (G. C Thakur, Chevron PTC) 


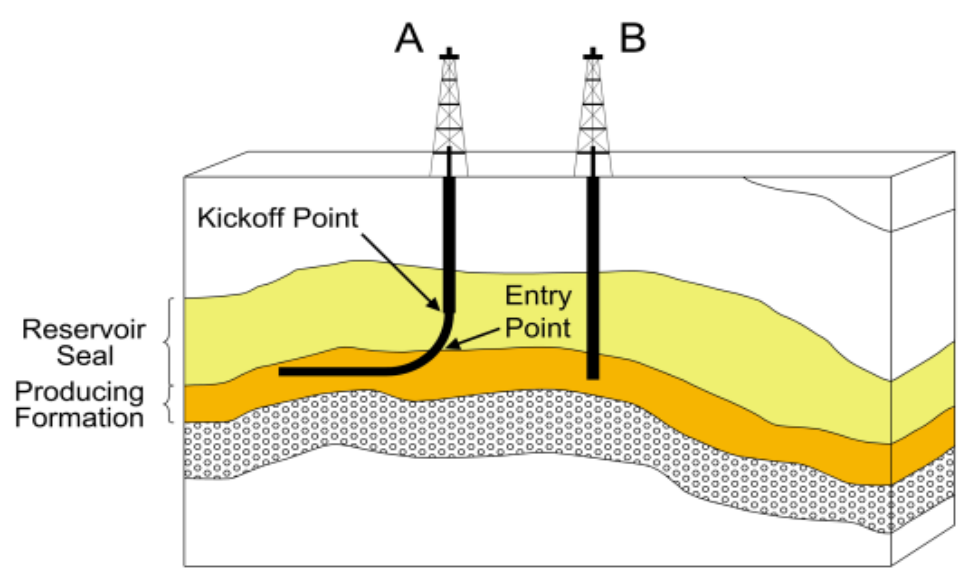

Figure II- 7 Greater Length of Producing Formation Exposed to the Wellbore in a Horizontal Well (A) Than in a Vertical Well (B)( Joshi ,SPA 16868)

However, Joshi (1988) found that horizontal wells are not viable in very thick reservoirs (500 to $600 \mathrm{ft}$ ) and also should be restrictively used with low vertical permeability. A decrease in vertical permeability results in an increase in vertical flow resistance for horizontal wells. Consequently, the productions of oil or gas will definitely be less than expected. The horizontal well technology has three major disadvantages as explained below (Joshi, 2003):

Horizontal wells considered costly as compared to vertical wells. For example, In the United States a new horizontal well drilled from the surface, costs 1.5 to 2.5 times more than a vertical well. A re-entry horizontal well costs about 0.4 to 1.3 times a vertical well cost.

In most cases only one zone at a time can be produced using a horizontal well. When the reservoir consists of multiple pay-zones, particularly with large differences in vertical depth, or large differences in permeability's, it is hard to drain all the layers using a single horizontal well and to perform work over jobs when multi entry completion installations exist. 
Usually a horizontal well accompanied with multi stage hydraulic fracturing treatments, which add to the overall drilling cost, in order to reach economical flow rate.

\subsection{Hydraulic fracturing}

Hydraulic Fracturing is a formation stimulation technique used to improve permeability, thus allowing gas to flow freely and unrestricted to the wellbore. Fracturing has become the industry standard nowadays ${ }^{(8)}$.Horizontal wells drilled in unconventional reservoirs accompanied with hydraulic fracturing can transfer the uneconomical production rate to a lucrative one.

To perform a hydraulic fracture treatment in a well, a fracturing fluid, mainly consists of water and special additives, is pumped down into the wellbore at a rate sufficient to achieve a pressure value in excess of the fracture gradient of the formation rock. To keep the fracture open after the injection stops, solid round sand is added to the fracture fluid. The propped hydraulic fracture then becomes a high permeability conduit through which the formation fluids can flow to the well. Figure II-8 shows an example of vertical well with a fracture. The purposes of performing hydraulic fracturing are:

- Bypass near-wellbore damage and return a well to its primary productivity

- Extend drainage area around the well bore through created conductive paths, hence the productivity increases in the well.

- To alter fluid flow in the formation and connect the productive zones. 


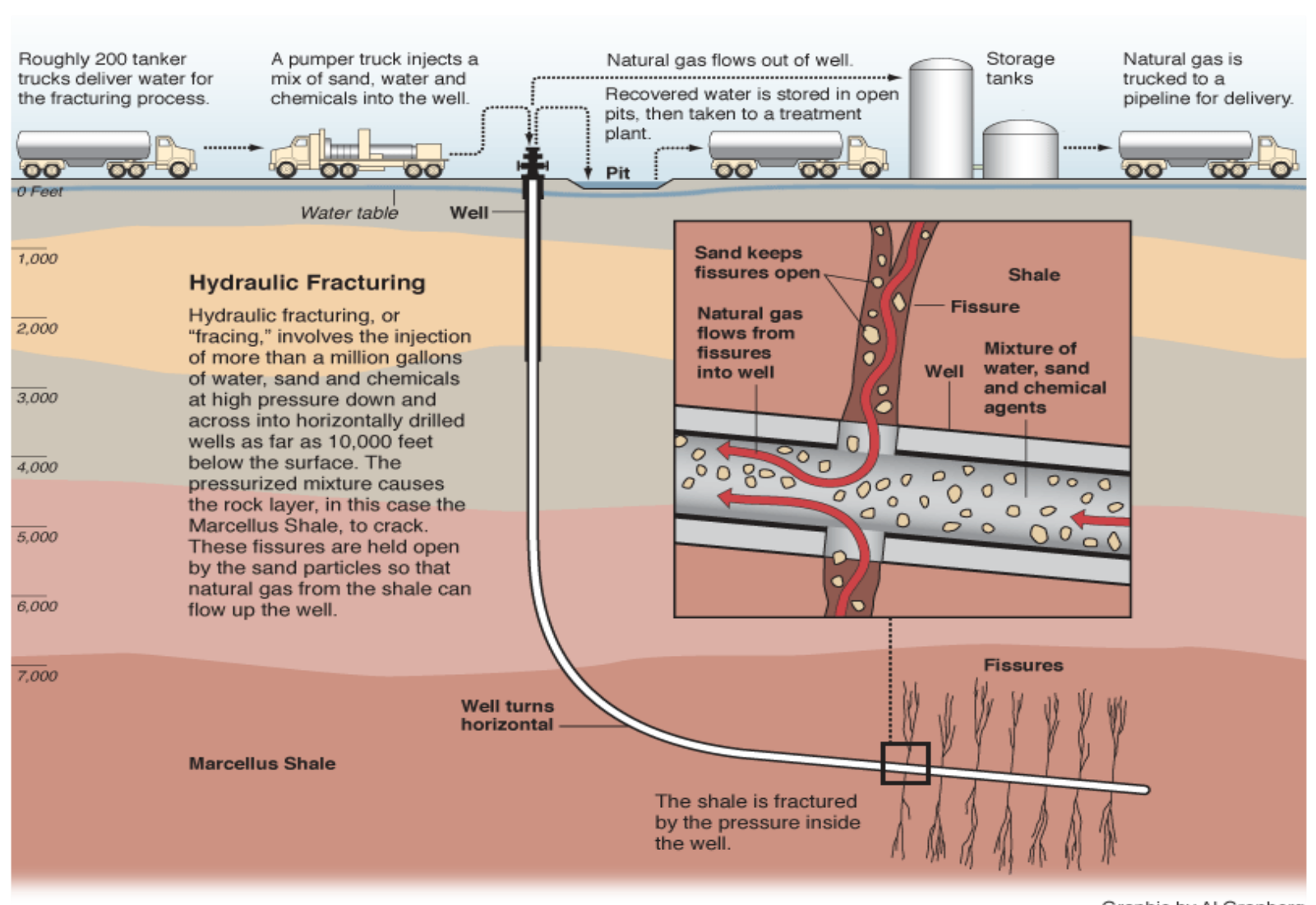

Graphic by Al Granberg

Figure II- 8 Flushing fractured horizontal well with proppant (Graphic by Al Granberg).

\subsubsection{Hydraulic Fracture Types}

Depending on well orientation, with respect to the minilmum horizontal stress, and length of the perforated interval, either a transverse or longitudinal fracture may be created.

If the horizontal well is drilled parallel to the minimum horizontal stress, and the perforated interval is shorter than four times the wellbore diameter. This is expected and the created fractures will be perpendicular to the horizontal well; i.e., transverse fractures will be created. If the horizontal well is drilled perpendicular to the minimum horizontal stress, the created fracture will be longitudinal. These two cases represent the two limiting and 
recommended cases. Figure II-9 shows both longitudinal and transverse fractures in a horizontal well.

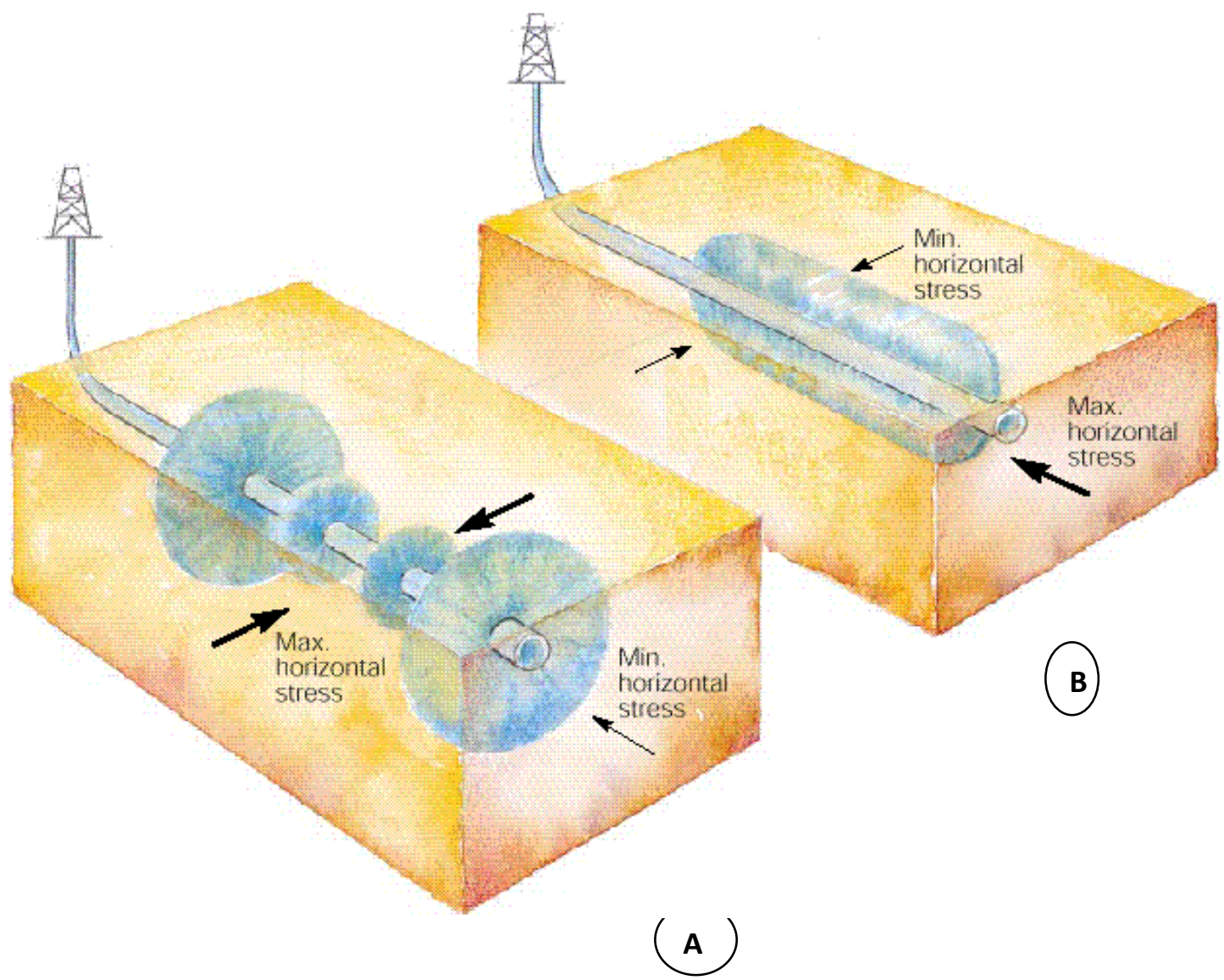

Figure II-9 shows both transverse fractures (A) and longitudinal fracture (B) in a horizontal well (Chen, C. and

Raghavan 1979)

\subsubsection{Dimensionless Fracture Conductivity (FCD)}

The dimensionless conductivity is the ratio of the fracture ability to carry flow divided by the ability of the formation to feed the fracture. If Fcd is more than 100 it is considered an infinite conductivity, if $\mathrm{F}_{\mathrm{CD}}$ is less than 100 it is considered a finite conductivity. For a given amount of proppant, two different types of fractures can be initiated or created, a short fat fracture can be created with a high value of fracture conductivity, $K f w$, or a longer, narrow fracture can be created with a lower value of fracture conductivity, $\mathrm{K} f w$. For low permeability 
reservoirs, a long, lower conductivity fracture is required. Figure II-10 shows the equation to calculate Dimensionless Fracture Conductivity $\left(\mathrm{F}_{\mathrm{CD}}\right)$. Figure II- 11 shows the pressure drop along the finite conductivity fracture and infinite conductivity fracture.

$$
\mathrm{F}_{\mathrm{CD}}=\left(\mathrm{K}_{\mathrm{F}} * \mathrm{~W}_{\mathrm{F}}\right) /\left(\mathrm{K} * \mathrm{X}_{\mathrm{F}}\right) \text { where: }
$$

$\mathrm{K}_{\mathrm{F}}$ : Fracture Permeability

$\mathrm{W}_{\mathrm{F}}$ : Fracture Width

K: Formation Permeability

$\mathrm{X}_{\mathrm{F}}$ : Fracture Half-length

If $\mathrm{F}_{\mathrm{CD}}$ is greater than 100 the fracture is finite Conductivity

Figure II-10 Fracture conductivity Equation.

\section{- Infinite-conductivity fracture}

Assumes that there is no pressure drop along the fracture

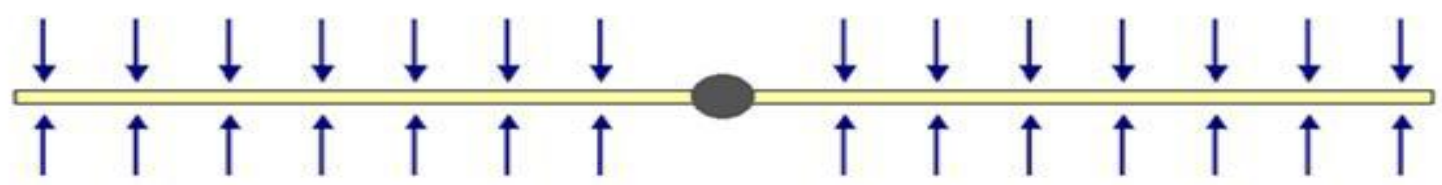

- Finite-conductivity fracture

Assumes that there is pressure drop along the fracture.

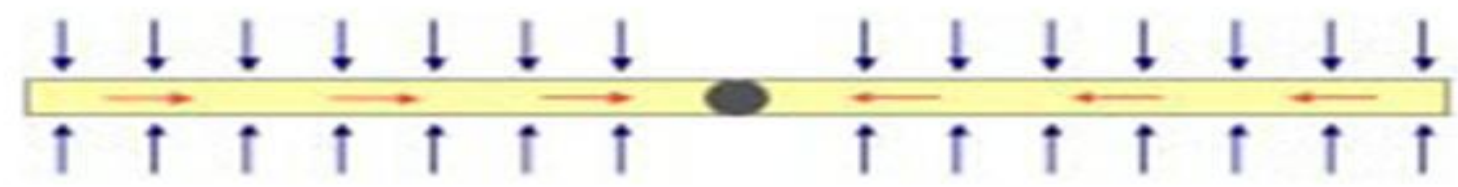

Figure II-11 Infinite-conductivity and finite-conductivity fractures (Boyer, C., Kieschnick 2006) 


\section{Chapter III Objective and Methodology}

The main objective of this research is to create a system of fractures in a horizontal well whose long-term performance is identical to a single effective (big fracture) of length equal to the spacing between the outermost fractures in the multiply fractures system. Figure III-12 shows a sketch of this interpretation.

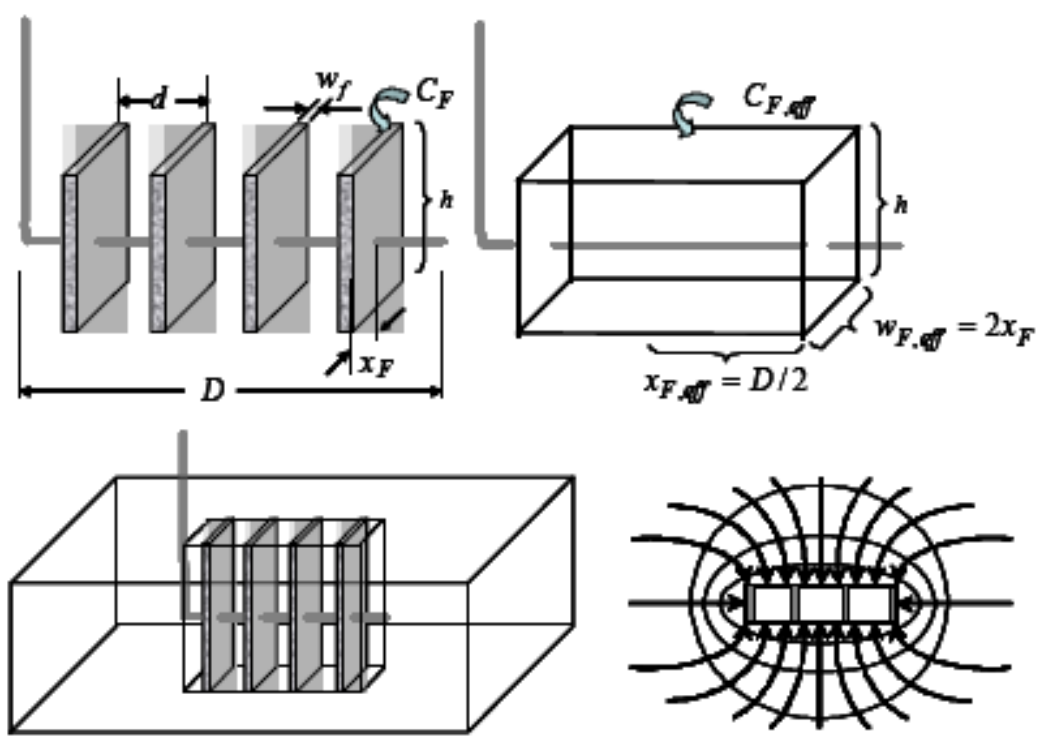

Figure III-12 Multiply-fractured-horizon-well in a tight formation and the effective (total) fracture concept ${ }^{(9)}$

The summary of the above concept is as follows:

Effective Fracture half length $\left(\mathrm{X}_{\mathrm{F}}\right)$ for longitudinal fracture = distance between Outermost multiply fractures $/ 2$

Effective Fracture Width $\left(\mathrm{W}_{\mathrm{F} \text {, eff }}\right)$ for Longitudinal fracture $=$ Total fracture length $(\mathrm{xf})$ for any one of multiply fractures.

The conductivity of this effective fracture depends on the permeability of the reservoir and the number, distance between, and conductivities of the individual hydraulic fractures. 
Fracture Height (h) is constant in both, effective fracture system and multiplies fractures.

$>$ The multiply fractures are uniformly spaced, have identical properties and are parallel with each other and perpendicular to the well.

The methodology to perform a system of fractures in a horizontal well was by using Schlumberger's Eclipse software to simulate production data for tight gas reservoir wells. Therefore, to make sure the data that were being used were correct, a Literature review has been done to collect all necessary data as input for Schlumberger's Eclipse software. Also, hydraulic fracture parameters were gathered to be used in the model.

The following steps were performed:

- Two models were built, one for multiply fractures and the other one for effective longitudinal fracture, to predict gas production profiles for hydraulically fractured horizontal wells in an unconventional gas reservoir.

- Total gas flow from both multiply fractures and effective longitudinal fracture has been measured.

- Evaluation of the various reservoir parameters to get the total gas flow from both models close or matched and this can be done through for example effective longitudinal fracture half-length change.

- Several simulation runs have been performed and comparisons were then made.

- The cases which were studied are multiply fractures of $300 \mathrm{ft}$ and $400 \mathrm{ft}$ fracture half length, and the number of multiply fractures was two, three, four and seven fractures.

A coal-bed methane template was used to enter gas reservoir properties for all cases. This template was the best option to represent unconventional gas production and all the cases were 
run for a 20 year period. The procedure for entering data through the template and performing a simulation are given in appendix A.

\subsection{Parameters used in the model}

The reservoir data are summarized below in the Table III-1.The simulation was run for 20 years for all runs shows some of the important parameters that were used in the modeling process. The reservoir was consisting of four layers which have the same thickness of $40 \mathrm{ft}$. The total reservoir thickness and depth were $120 \mathrm{ft}$ and $7000 \mathrm{ft}$ respectively. The shape of the reservoir was a rectangular of dimensions $4000 \mathrm{ft}$ by $1000 \mathrm{ft}$ except for one case which was $4000 \mathrm{ft}$ by $2000 \mathrm{ft}$. Therefore, this reservoir well, horizontal well, makes a drainage area of almost 92 acres. The reservoir (tight gas) permeability was equal to $0.001 \mathrm{md}$. Also, a porosity value of three percent was used in the model. Initial reservoir pressure and initial water saturation was 3500 psi and 15 percent respectively. All above data was based on literature review.

Table III- 1 reservoir data used in the model

\begin{tabular}{|l|c|}
\hline \multicolumn{1}{|c|}{ Parameters } & Values \\
\hline Reservoir depth & $7000 \mathrm{ft}$ \\
\hline Peservoir total thickness & $\mathbf{1 2 0 f t}$ \\
\hline Porosity \% & 30 years \\
\hline Reservoir permeability & $\mathbf{3}$ \\
\hline Reservoir pressure & 3500 psi \\
\hline
\end{tabular}




Reservoir area

Horizontal lateral section length

Number of layers in the reservoir

Initial water saturation, fraction
4000 ft by 1000 ft (92 acres)

$3000 \mathrm{ft}$

4 layers of $20 \mathrm{ft}$ thickness each

0.15

Table III- 2 below summarizes the fracture parameters that have been used in the model. Also, some other data such as fluid properties are shown in Table III-3.

Table III- 2 Fracture Parameters used in the model

\begin{tabular}{|l||l||}
\hline \multicolumn{1}{|c|}{ Parameters } & \multicolumn{1}{|c|}{ Values } \\
\hline Multiply fractures Half Length (ft) & $\mathbf{3 0 0 , 4 0 0}$ \\
\hline Width (in) & $\mathbf{0 . 0 1}$ \\
\hline Height of the fracture (ft) & $\mathbf{1 2 0}$ \\
\hline Number of multiply fractures & $\mathbf{2 , 3 , 4 , 7}$ \\
\hline X-center (ft) & Equally divided on no. of fracs. \\
\hline \hline Y-center (ft) & $\mathbf{5 0 0}$ \\
\hline \hline Permeability (mD) & $\mathbf{2 0 0 0 0}$ \\
\hline \hline Porosity fraction & $\mathbf{0 . 2}$ \\
\hline Top of Fracture, $\mathrm{ft}$ & $\mathbf{7 0 0 0}$ \\
\hline Bottom of Fracture, $\mathrm{ft}$ & $\mathbf{7 1 2 0}$ \\
\hline
\end{tabular}


Table III- 3 Fluid properties and Adsorption data

\begin{tabular}{|c|c|}
\hline \multicolumn{2}{|l|}{ Fluid properties } \\
\hline Standard Pressure ,psia & 14.7 \\
\hline Standard Temperature, Fahrenheit & 60 \\
\hline Reference Temperature, Fahrenheit & 120 \\
\hline \multicolumn{2}{|l|}{ Well Production Controls } \\
\hline Pwf, psia & 350 \\
\hline \multicolumn{2}{|l|}{ Adsorption data } \\
\hline Diffusion coefficient, $\mathrm{ft}^{\wedge} 2 /$ day & 1 \\
\hline Sorption Time, day & 62 \\
\hline Langmuir Pressure, psia & 635 \\
\hline Langmuir Concentration, MSCF/ton & 0.08899 \\
\hline
\end{tabular}

\section{2- Model generation Top view}

Figure III-13 below shows a horizontal well with three multiply fractures as an example of model generation by Eclipse Schlumberger's software whereas Figure III-14 shows a horizontal well with an effective longitudinal fracture. 


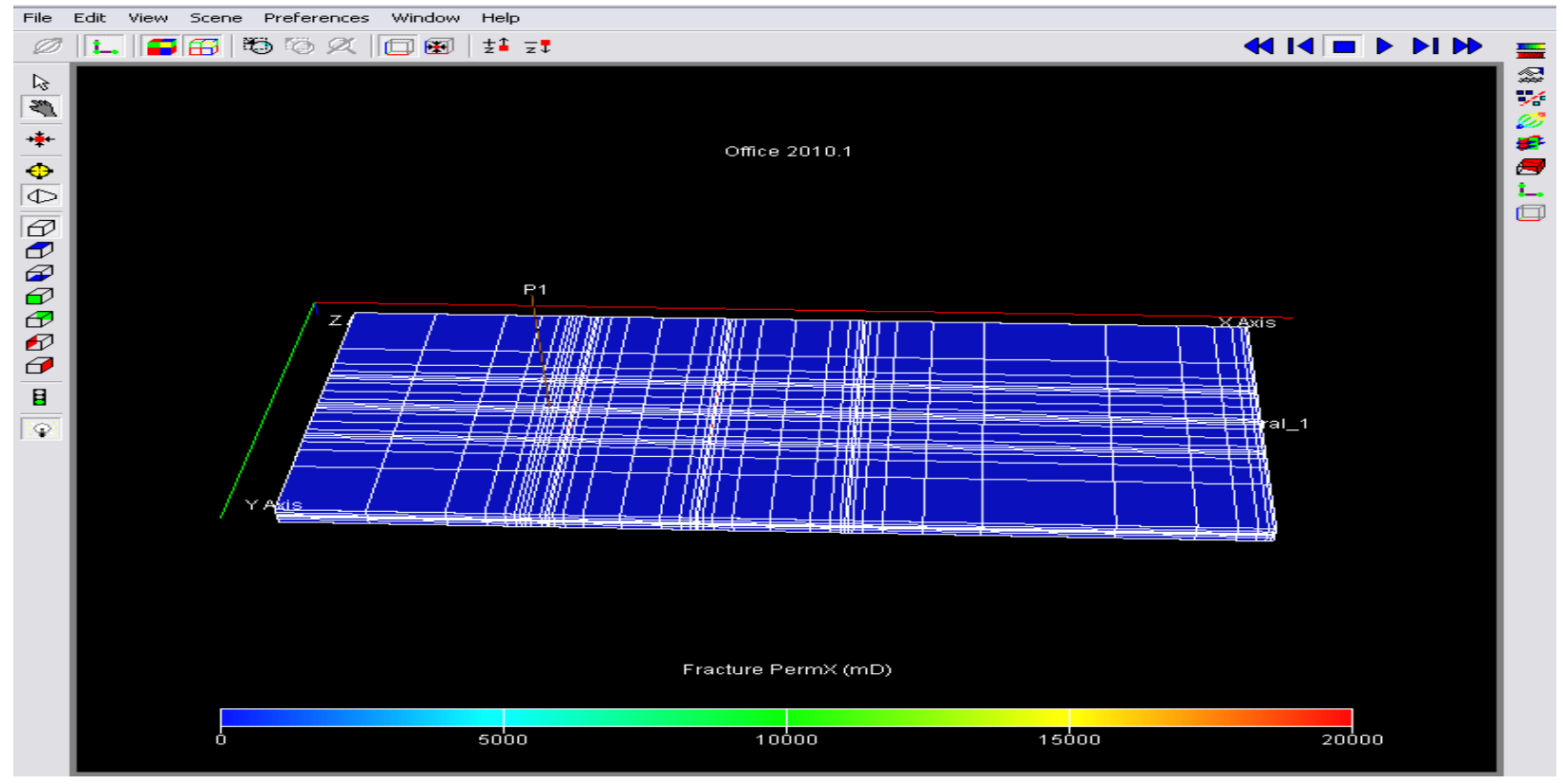

Figure III-13 Top view of the model with three multiply fractures

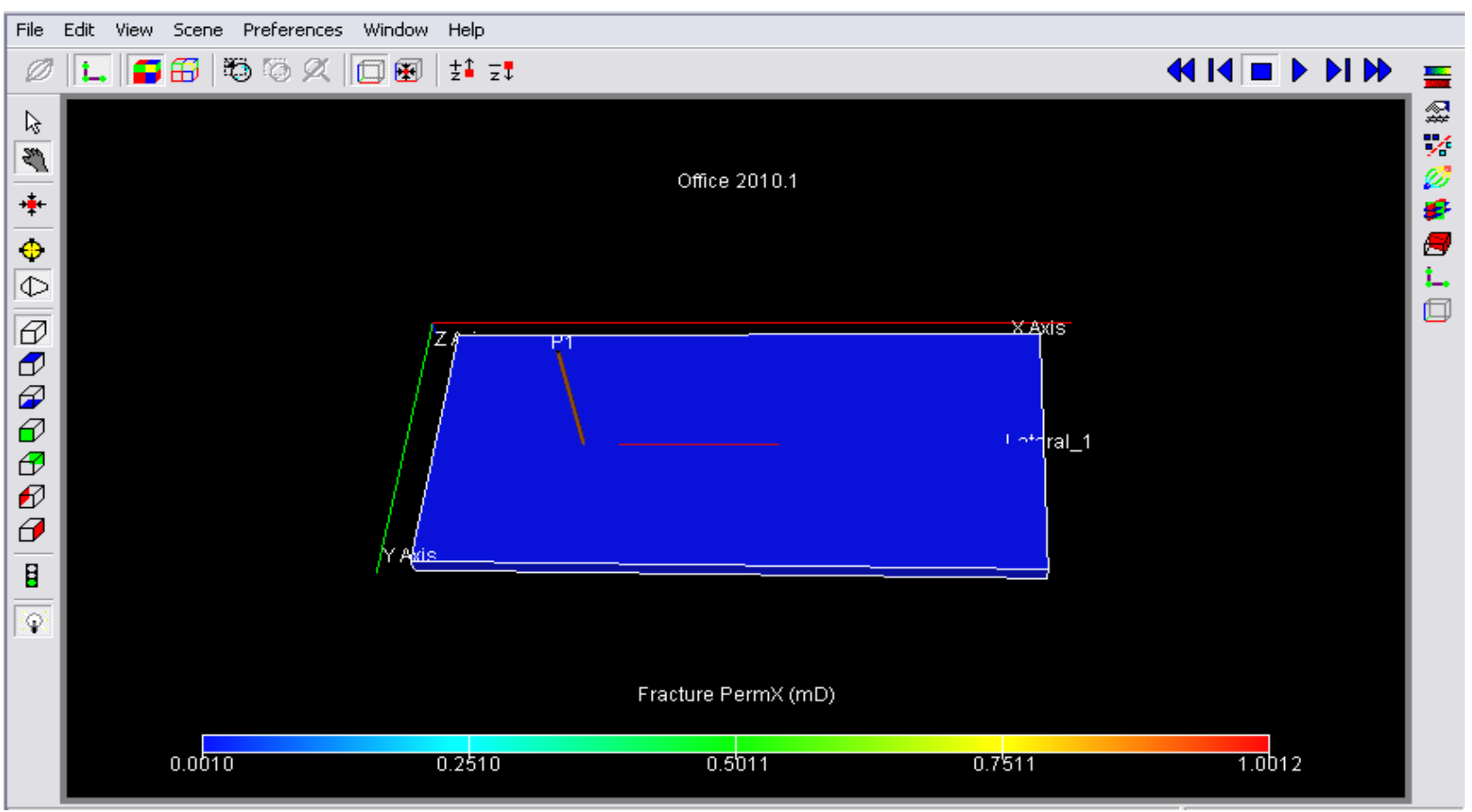

Figure III-14 Top view of effective longitudinal fracture 


\section{Chapter IV Results and Discussion}

In this chapter, the results from the simulation runs are presented with discussion on the production performance of multiply fractures vs. effective fracture. One horizontal well with a lateral section of $3000 \mathrm{ft}$ was considered in this study. Two, three, four and seven transverse fractures were in a horizontal well and evaluated with effective longitudinal fracture for each case. The transverse fractures were equally spaced in each case. The Raghavan and Chen, 1997 (9) concept has been followed but the effective longitudinal fracture half-length has been modified during the simulation runs for each case separately to achieve the closest production match from both transverse fractures and effective longitudinal fracture. The production profile was generated for a period of twenty years due to the long term production capability of unconventional gas reservoirs. Table IV-1 and IV-2 below summarize the results of the modifications necessary to achieve a good match.

\subsection{Multiply fractures of $300 \mathrm{ft}$ fracture half-length with effective longitudinal fracture.}

\section{a) Two-fracture case}

Figure IV-1 below compares the production from two fractures with fracture half-length of $300 \mathrm{ft}$ against corresponding effective longitudinal fracture. The properties of two fractures are identical. Effective longitudinal half-length fracture has been modified during the runs from $250 \mathrm{ft}$ to $650 \mathrm{ft}$ to simulate the production from two fractures. The concept of the Raghavan and Chen, $1997^{(9)}$ has been followed. The modifications brought the total gas production very close to the two fracture case. 


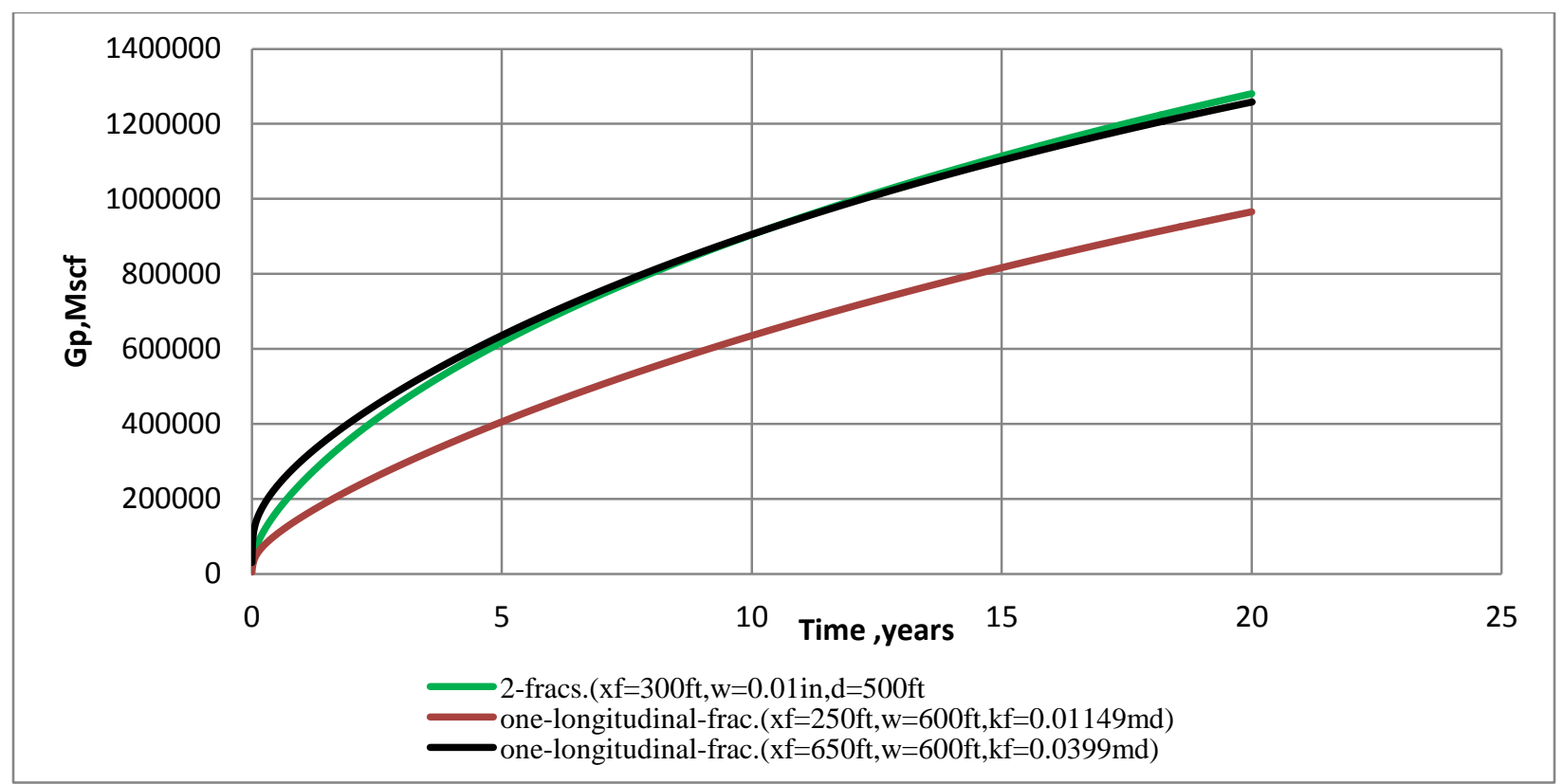

Figure IV- 1 two fractures vs. effective longitudinal fracture

\section{b) Three -fracture case}

Figure IV-2 shows three multiply fractures $(x f=300 \mathrm{ft}$ ) with corresponding effective longitudinal fracture. Effective longitudinal half-length fracture has been modified during runs

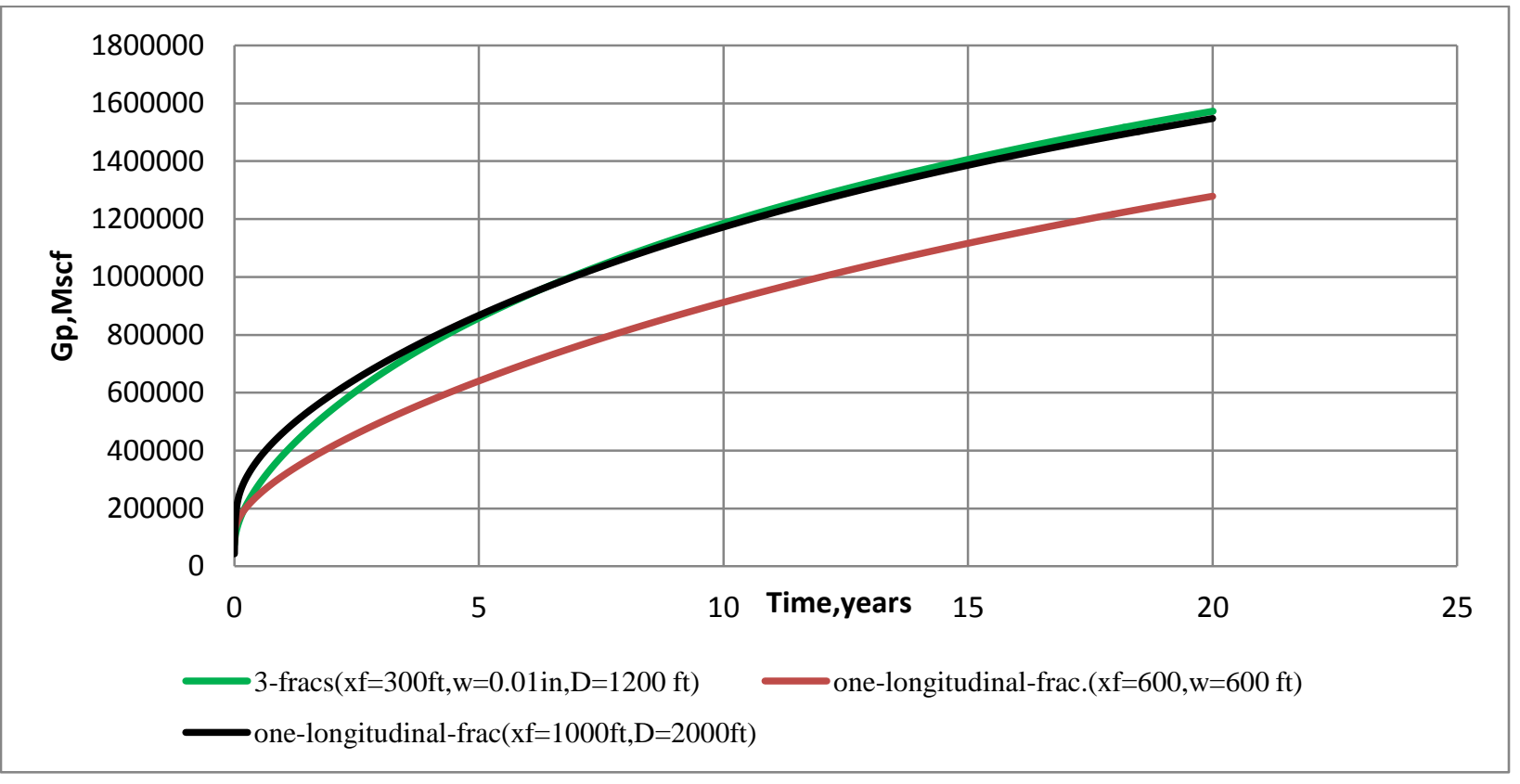

Figure IV- 2 three fractures vs. effective longitudinal fracture 
from $600 \mathrm{ft}$ to $1000 \mathrm{ft}$ to simulate the two multiply fractures in terms of total gas production. Therefore, as seen from the graph above the total gas production from the effective longitudinal fracture and three multiply fractures were very close.

\section{c) Four multiply fractures case}

Figure IV-3 compares production from four fractures with effective longitudinal fracture.

The effective fracture in this case has been modified after several runs to get the closest match with four fractures in terms of gas production. The fracture half-length of effective fracture has been modified during runs from $600 \mathrm{ft}$ to $1200 \mathrm{ft}$.

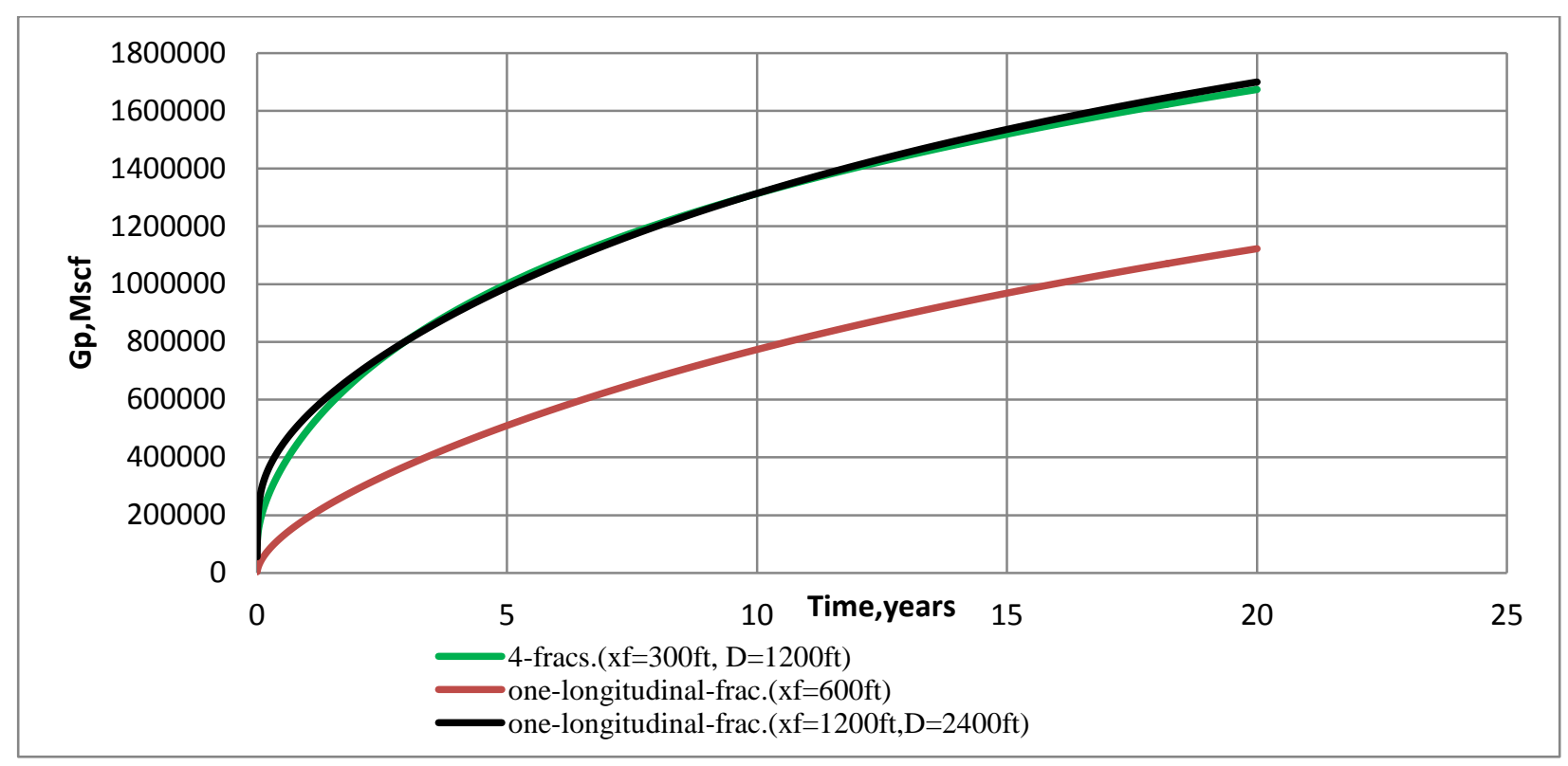

Figure IV- 3 four fractures vs. effective longitudinal fracture 


\section{d) Seven multiply fractures case}

Figure IV-4 compares production from seven fractures with effective longitudinal fracture. The effective longitudinal fracture half-length has been modified to get the best match with seven fractures in terms of total gas production. The effective fracture half-length has been modified during runs from $700 \mathrm{ft}$ to $1500 \mathrm{ft}$.

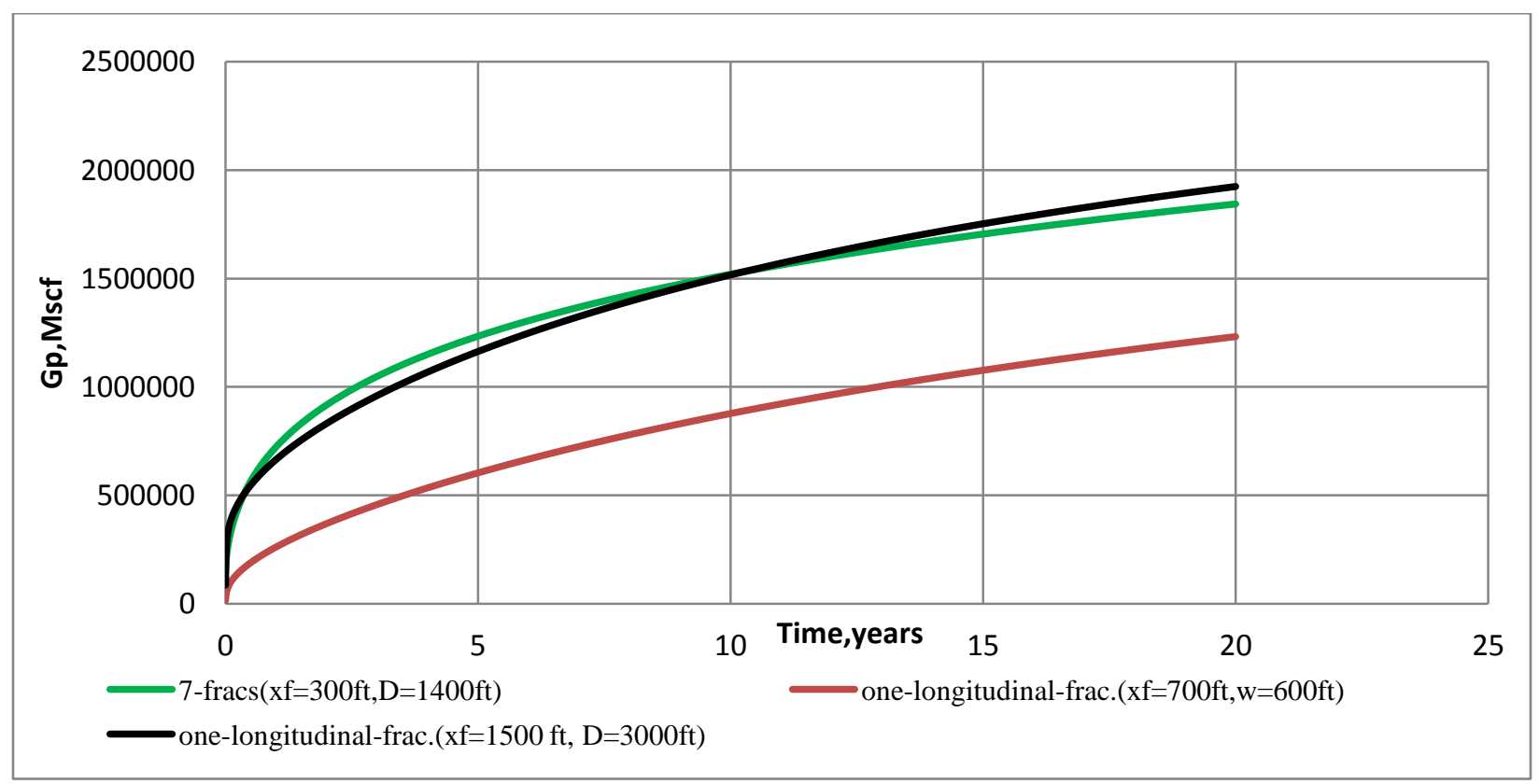

Figure IV- 4 seven fractures vs. effective longitudinal fracture 


\subsection{Multiply fractures of $\mathbf{4 0 0} \mathrm{ft}$ fracture half-length with effective longitudinal fracture.}

\section{Two fracture case}

Figure IV-5 below compares the production from two fractures, whose fracture halflength $(x f)=400 \mathrm{ft}$, with corresponding effective longitudinal fracture. Effective longitudinal half-length fracture has been modified during runs from $600 \mathrm{ft}$ to $900 \mathrm{ft}$ to simulate the two fractures in terms of total gas production.

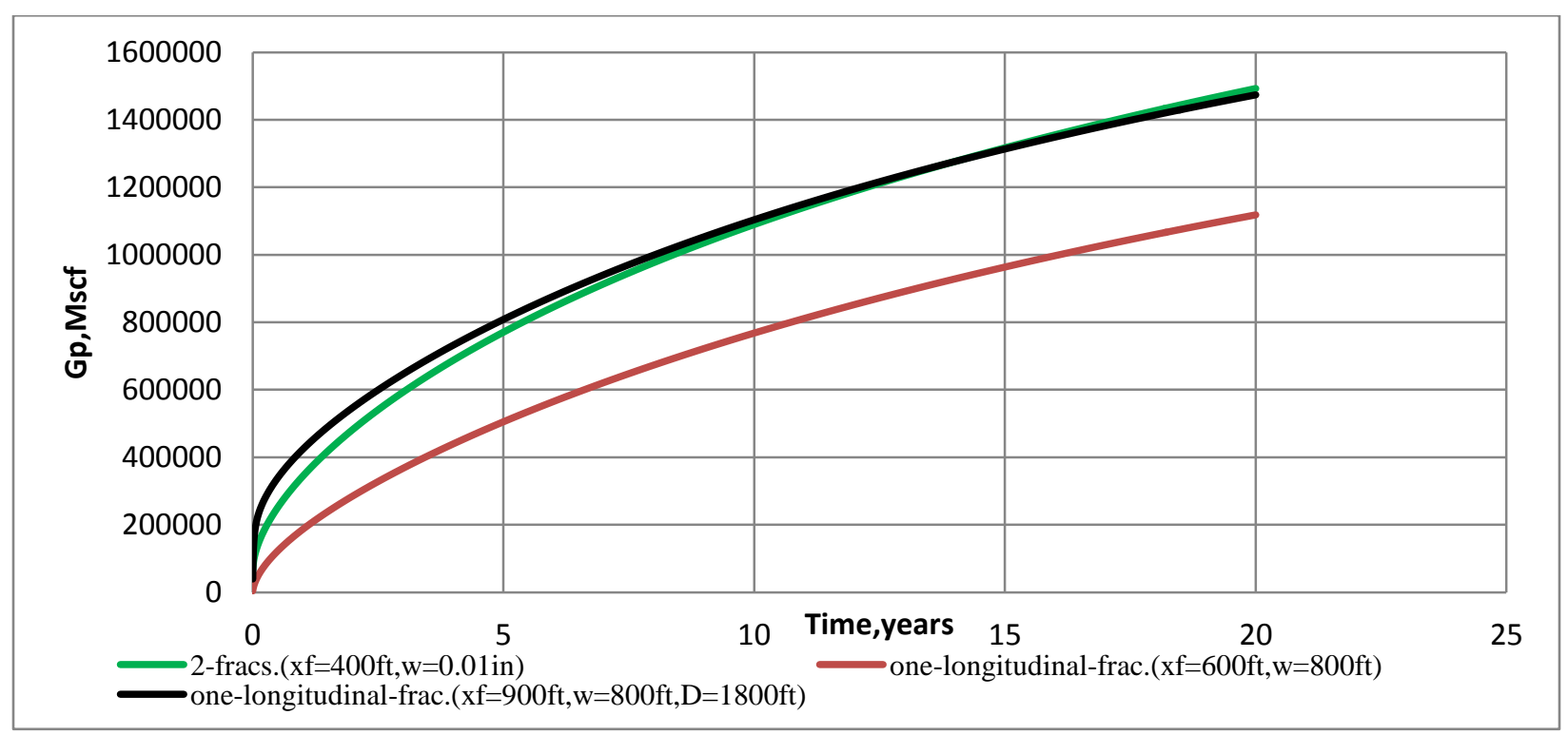

Figure IV- 5 two fractures vs. effective longitudinal fracture

\section{Three fracture case}

Figure IV-6 compares the production from three fractures with effective longitudinal fracture. In this case the effective longitudinal fracture half-length has been modified during simulation runs from $600 \mathrm{ft}$ to $1200 \mathrm{ft}$ to achieve the match with total gas production of three fractures. The increase in fracture half-length was doubled in this case as seen below. 


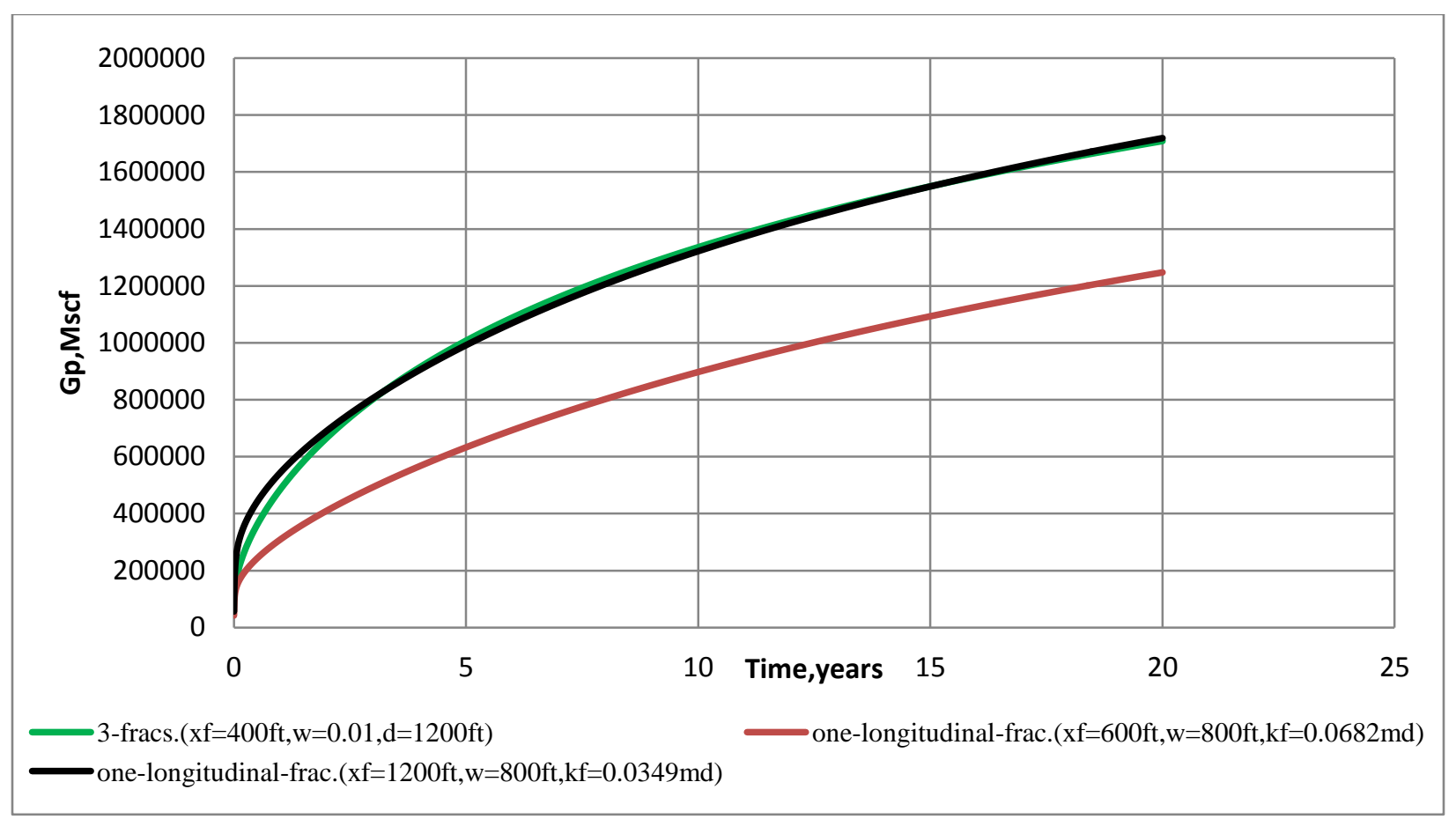

Figure IV- 6 three fractures vs. effective longitudinal fracture

\section{Four fracture case}

Figure IV-7 compares production from four fractures with effective longitudinal fracture. In this case the effective longitudinal fracture has been modified during simulation runs from $600 \mathrm{ft}$ to $1400 \mathrm{ft}$. 


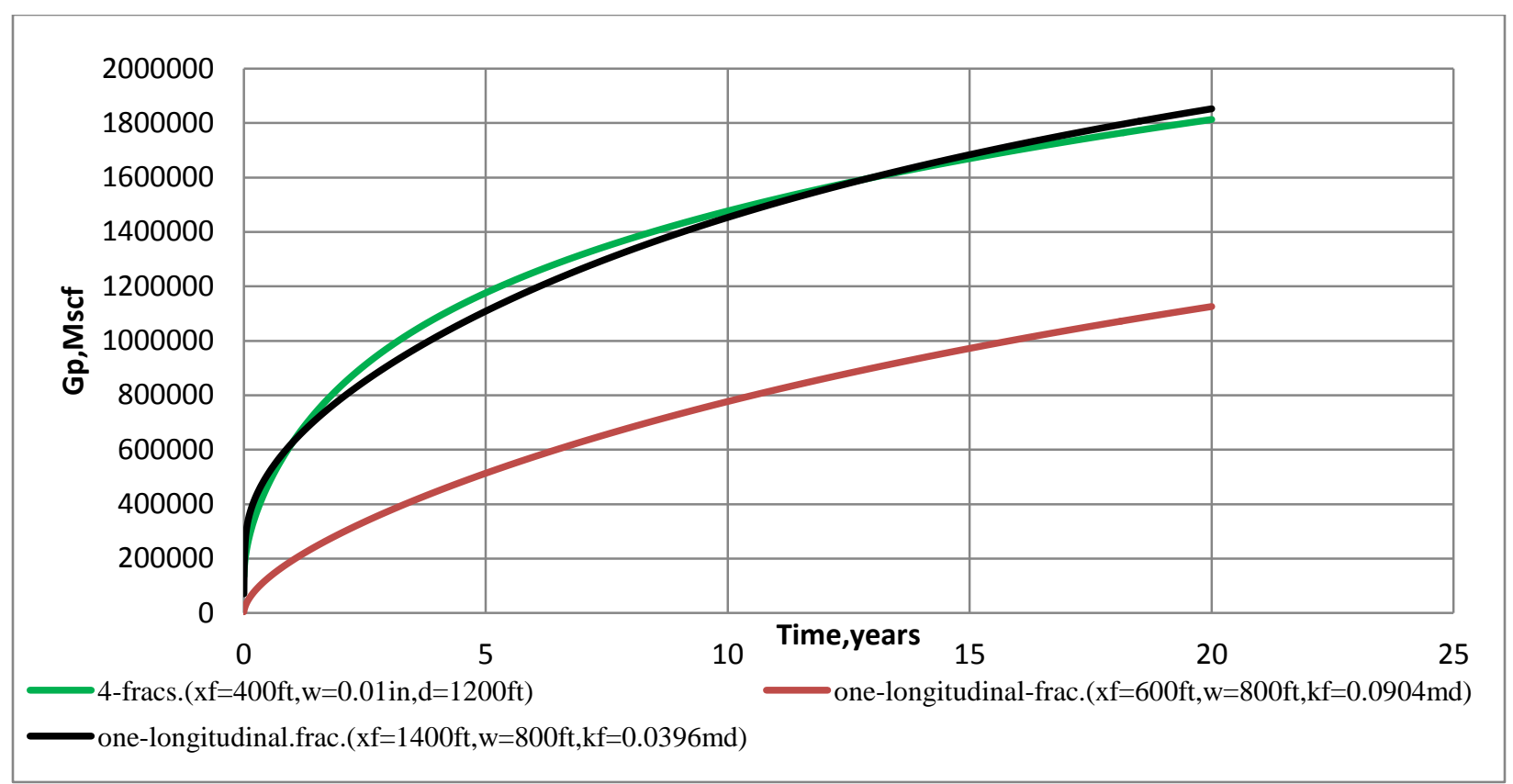

Figure IV- 7 four multiply fractures vs. effective longitudinal fracture

\section{Seven fracture case}

Both figures IV-8 and IV-9 compare production from seven fractures with effective longitudinal fracture. Figure IV-8 does not show a good match between the production from the effective longitudinal fracture and seven fractures even after several simulation runs due to high number in fractures in such a small derange area. However, Figure IV-9 below shows good results because the reservoir dimensions has been increased from (4000ft by $1000 \mathrm{ft})$ to $(4000 \mathrm{ft}$ by $2000 \mathrm{ft})$. The effective longitudinal fracture has been modified during runs from $700 \mathrm{ft}$ to1800 ft. 


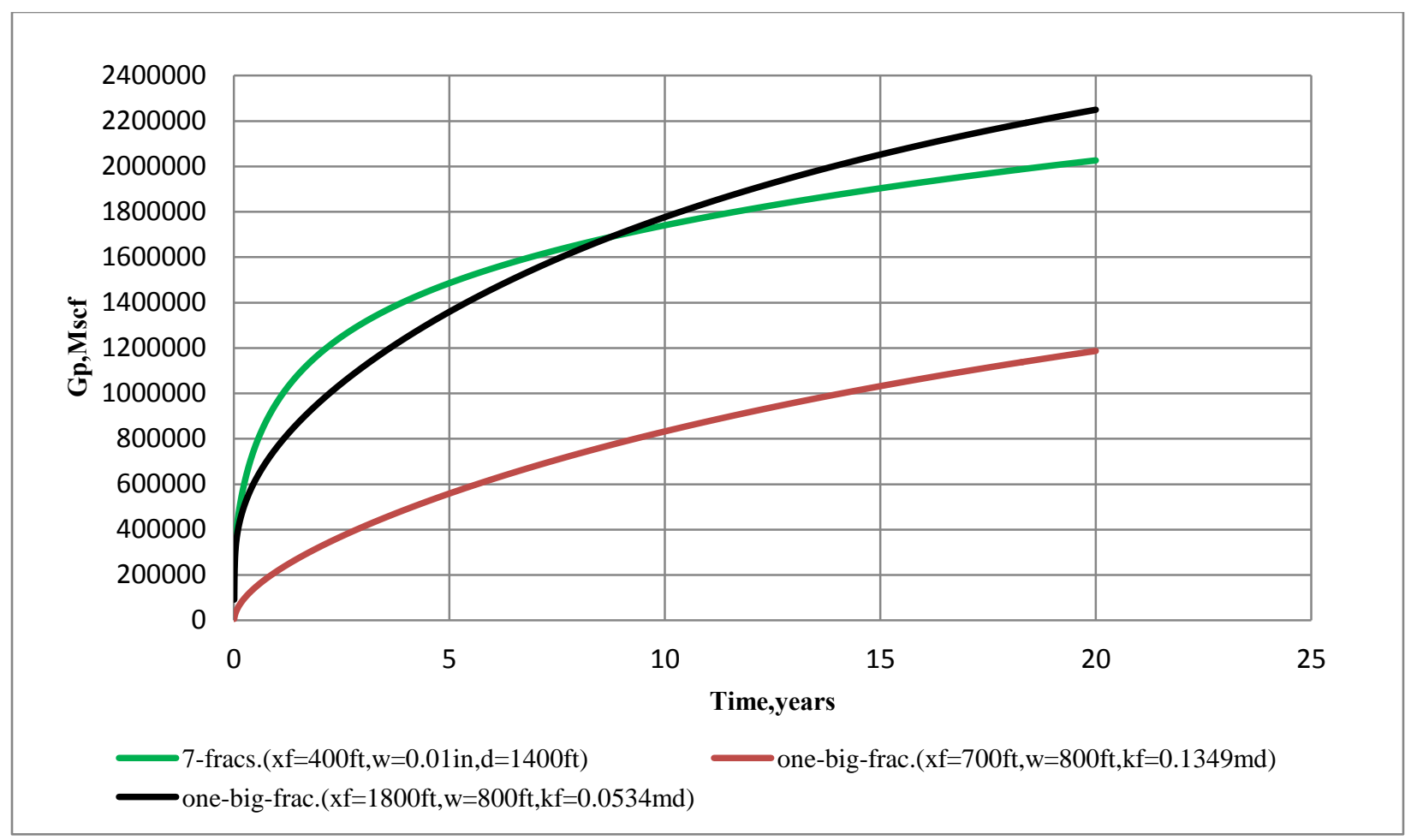

Figure IV- 8 seven fractures vs. effective longitudinal fracture (reservoir dimensions $=4000 \mathrm{ft}$ by $1000 \mathrm{ft}$ )

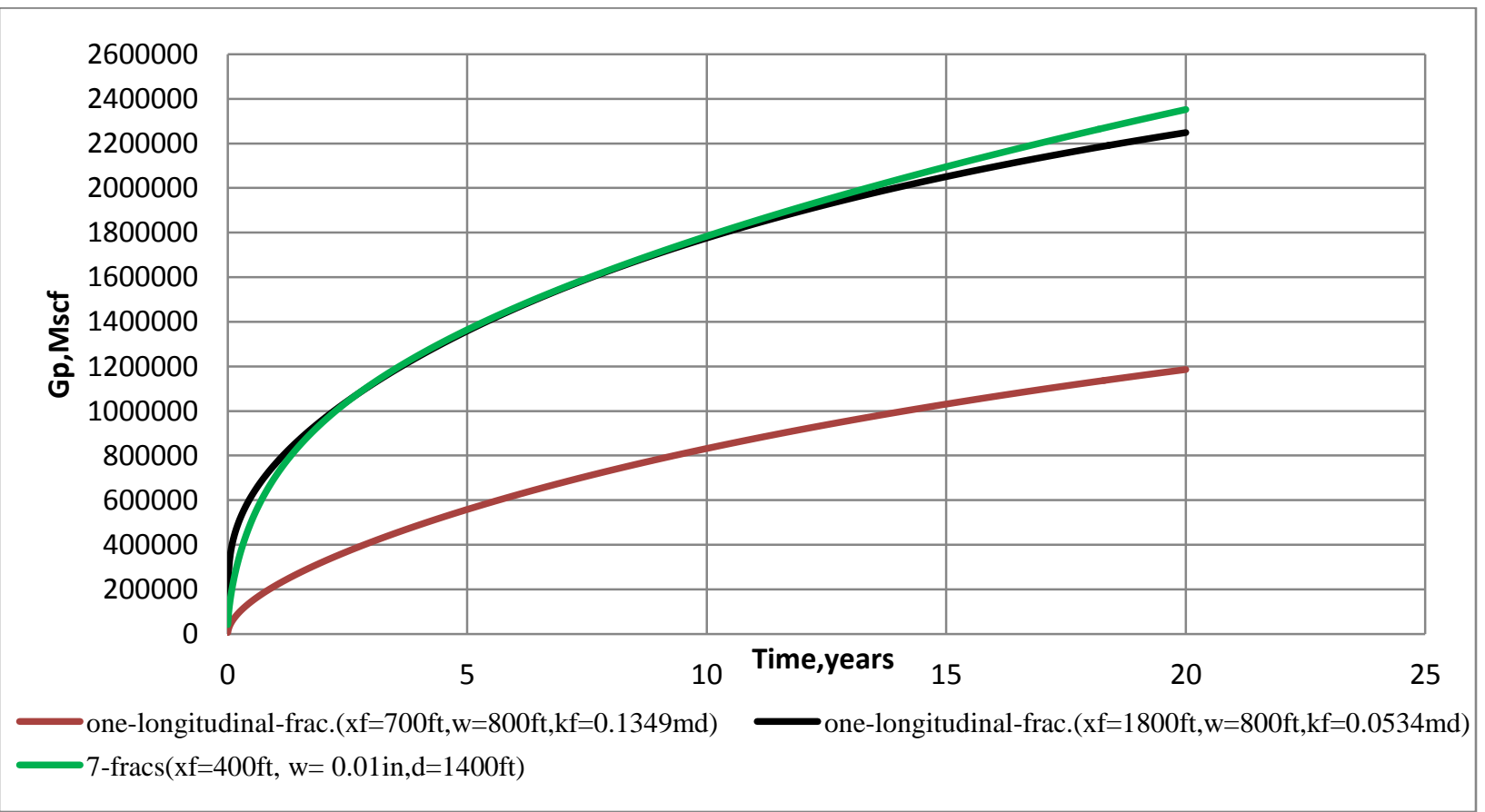

Figure IV- 9 seven fractures vs. effective longitudinal fracture (reservoir dimensions $=4000 \mathrm{ft}$ by $2000 \mathrm{ft}$ ) 
Table IV- 1 summary results of multiply fractured $(x f=300 f t)$ horizontal well and effective longitudinal fracture.

\begin{tabular}{|c|c|c|c|c|c|c|c|c|}
\hline \multicolumn{9}{|c|}{ Multiply fractured horizontal well $(\mathrm{xf}=300 \mathrm{ft})$ and effective longitudinal fracture summary } \\
\hline \multirow[b]{2}{*}{ Fracture. Property } & \multicolumn{2}{|c|}{ Case 1} & \multicolumn{2}{|r|}{ Case 2} & \multicolumn{2}{|c|}{ Case 3} & \multicolumn{2}{|c|}{ Case 4} \\
\hline & $\mathrm{Nf}=2$ & $\begin{array}{l}\text { Longitudinal } \\
\text { Fracture }\end{array}$ & $\mathrm{Nf}=3$ & $\begin{array}{l}\text { Longitudinal } \\
\text { Fracture }\end{array}$ & $\overline{\mathrm{Nf}=4}$ & $\begin{array}{l}\text { Longitudinal } \\
\text { Fracture }\end{array}$ & $\mathrm{Nf}=7$ & $\begin{array}{l}\text { Longitudinal } \\
\text { Fracture }\end{array}$ \\
\hline $\begin{array}{l}\text { Fracture half length( } \\
\text { xf, ft)Initial value }\end{array}$ & 300 & $250 \mathrm{ft}$ & 300 & $600 \mathrm{ft}$ & 300 & $600 \mathrm{ft}$ & 300 & $700 \mathrm{ft}$ \\
\hline $\begin{array}{l}\text { Fracture half- } \\
\text { length(Match value) }\end{array}$ & & $650 \mathrm{ft}$ & & $101000 \mathrm{ft}$ & & $121200 \mathrm{ft}$ & & $1500 \mathrm{ft}$ \\
\hline $\begin{array}{l}\text { Out-most distance } \\
\text { between fractures. }\end{array}$ & $500 \mathrm{ft}$ & & $1200 \mathrm{ft}$ & & $1200 \mathrm{ft}$ & & $1400 \mathrm{ft}$ & \\
\hline $\begin{array}{l}\text { Fracture } \\
\text { permeability(kf,md) }\end{array}$ & 20000 & 0.477 & 20000 & 0.501 & 20000 & 0.556 & 20000 & 0.687 \\
\hline Fracture width & 0.01 in & $2600 \mathrm{ft}$ & 0.01 in & $600 \mathrm{ft}$ & 0.01 in & $600 \mathrm{ft}$ & 0.01 in & $600 \mathrm{ft}$ \\
\hline
\end{tabular}

Table IV- 2 summary results of multiply fractured $(x f=400 f t)$ horizontal well and effective longitudinal fracture.

Multiply-fractured-horizontal-well(xf=400ft) and effective- longitudinal fracture summary.

\begin{tabular}{|c|c|c|c|c|c|c|c|c|}
\hline \multirow[b]{2}{*}{ Fracture. Property } & \multicolumn{2}{|c|}{ Case 1 } & \multicolumn{2}{|r|}{ Case 2} & \multicolumn{2}{|c|}{ Case 3} & \multicolumn{2}{|c|}{ Case 4} \\
\hline & $\mathrm{Nf}=2$ & $\begin{array}{l}\text { Longitudinal } \\
\text { Fracture }\end{array}$ & $\mathrm{Nf}=3$ & \begin{tabular}{|l} 
Longitudinal \\
Fracture
\end{tabular} & $\mathrm{Nf}=4$ & $\begin{array}{l}\text { Longitudinal } \\
\text { Fracture }\end{array}$ & $\mathrm{Nf}=7$ & $\begin{array}{l}\text { Longitudinal } \\
\text { Fracture }\end{array}$ \\
\hline $\begin{array}{l}\text { Fracture half length( } \\
\mathrm{xf}, \mathrm{ft}) \text { initial value }\end{array}$ & $\overline{4400}$ & $600 \mathrm{ft}$ & 400 & $600 \mathrm{ft}$ & $\overline{4400}$ & $600 \mathrm{ft}$ & 400 & $700 \mathrm{ftft}$ \\
\hline $\begin{array}{l}\text { Fracture half } \\
\text { length(match value) }\end{array}$ & & $2900 \mathrm{ft}$ & & $1200 \mathrm{ft}$ & & $1400 \mathrm{ft}$ & & $1700 \mathrm{ft}$ \\
\hline $\begin{array}{l}\text { Out-most distance } \\
\text { between fractures. }\end{array}$ & $1200 \mathrm{ft}$ & & $1200 \mathrm{ft}$ & & $1200 \mathrm{ft}$ & & $1400 \mathrm{ft}$ & \\
\hline $\begin{array}{l}\text { Fracture } \\
\text { permeability }(\mathrm{kf}, \mathrm{md})\end{array}$ & 20000 & 0.0321 & 20000 & 0.0349 & 20000 & 0.0396 & 20000 & 0.0534 \\
\hline Fracture width & 0.01 in & $800 \mathrm{ft}$ & $0.01 \mathrm{in}$ & $800 \mathrm{ft}$ & 0.01 in & $800 \mathrm{ft}$ & $0.01 \mathrm{in}$ & $800 \mathrm{ft}$ \\
\hline
\end{tabular}




\section{Chapter V. Conclusions and recommendations}

The main purpose of this study is to create a system of fractures in a horizontal well whose long-term performance is identical to a single effective longitudinal fracture of length equal to the spacing between the outermost fractures in the multiply fractures system.

The approach to perform a system of fractures in a horizontal well was by using Schlumberger's Eclipse software to simulate production data for tight gas reservoir wells. Therefore, to make sure the data that were being used were correct, a Literature review has been done to collect all necessary data as input for Schlumberger's Eclipse software. Also, hydraulic fracture parameters were gathered to be used in the model. The following points have been reached:

- Outer most distance between multiple fractures plays a significant role in determining the fracture-half-length of the alternative effective longitudinal fracture.

- The parameter that has a major impact in this study was effective longitudinal fracture half-length in all cases.

- Effective fracture width modification has limited effect on just early period of gas production and hence, results were not shown in this research.

- To use a heterogeneous formation properties such as porosity of the reservoir and permeability and figuring out its effects on gas production from tight gas formation( dual porosity formation) 


\section{NOMENCLATURE}

$\mathrm{PR}=$ Reservoir pressure (psia)

$\mathrm{Pi}=$ Initial Reservoir Pressure, $(\mathrm{psia})$

$\mathrm{P} w f=$ Bottom-hole flowing pressure (psia)

$\mathrm{K}=$ reservoir permeability, md

$\varphi=$ Porosity $(\%)$

$\mathrm{h}=$ Thickness $(\mathrm{ft})$

$\mathrm{P}=$ Pressure (psia)

$\mathrm{P}=$ Pseudo-pressure, $\mathrm{psi} 2 / \mathrm{cp}$

$\mathrm{B}=$ formation volume factor

$\mu=$ gas viscosity, $\mathrm{cp}$

$\mathrm{q}=$ Gas rate (Mscf/day)

$\mathrm{t}=$ Time $($ years $)$

$\mathrm{L}=$ Length of lateral $(\mathrm{ft})$

$\mathrm{Gp}=$ Cumulative gas production (Mscf)

$\mathrm{Re}=$ drainage radius, $\mathrm{ft}$

$\mathrm{Rw}=\mathrm{well}$ radius, $\mathrm{ft}$

$\mathrm{S}=$ skin factor

$\mathrm{Xf}=$ fracture half length, $\mathrm{ft}$

$\mathrm{Kf}=$ fracture permeability, $\mathrm{md}$

$\mathrm{Wf}=$ width of fracture, in

Fcd $=$ dimensionless fracture conductivity

$\mathrm{Nf}=$ number of fractures 


\section{References}

1. EIA. 2007. International Energy Outlook, Chapter 4: Natural Gas. http://tonto.eia.doe.gov/FTPROOT/forecasting/0484 (2007). pdf. Accessed: May 2007.

2. EIA. 2008. Annual Energy Outlook 2008 with Projections to 2030. http://www.eia.doe.gov/oiaf/aeo/pdf/ 0383 (2008).pdf. Accessed: June 2008.

3. Masters JA: "Deep Basin Gas Trap, Western Canada," AAPG Bulletin (1979) 63, No. 2: 152.

4. Kawata Y and Fujita K: "Some Predictions of Possible Unconventional Hydrocarbon Availability Until 2100," SPE 68755 presented at the SPE Asia Pacific Oil and Gas Conference, Jakarta, Indonesia, (April 17-19, 2001).

5. Holditch SA: "Tight Gas Sands," SPE Paper 103356, Distinguished Author Series (2006).

6. EIA. 2008. Annual Energy Outlook 2008 with Projections to 2030. http://www.eia.doe.gov/oiaf/aeo/pdf/0383(2008).pdf. Accessed: June 2008.

7. EIA. 2008. Annual Energy Outlook 2008 with Projections to 2030. http://www.eia.doe.gov/oiaf/aeo/pdf/0383(2008).pdf. June 2008.

8. Boyer, C., Kieschnick, J., Suarez-Rivera, R., Lewis, R., and Walter, G. 2006. Schlumberg er. Oilfield Review. Producing Gas from Its Source. Pp 36-49. Autumn 2006.

9. Chen, C. and Raghavan, R.(1997). A Multiply-Fractured Horizontal Well in a Rectangular Drainage Region. Soc. Eng.Jour. Vol. 2,(Dec.) 455-465.

10. Data after Rogner H: "An Assessment of World Hydrocarbon Resources," Institute for Integrated Energy System, University Of Victoria (1997). 
11. Lane H.S. and A. T. Watson, and D.E. Lancaster, "Identifying and Estimating Desorption from Devonian Shale Gas Production Data”, SPE 19794, 1989.

12. Joshi, S.D.: "A Review of Horizontal Well and drainhole Technology," paper SPE 16868 presented at the 1987 Annual Technical Conference and Exhition, Dallas, Sep. 27-30.

13. Joshi, S.D.: "Augmentation of well productivity using slant and horizontal wells", Journal of Petroleum Technology, Vol. 40, pp. 729-739 (June 1988).

14. Rogner H-H: “An Assessment of World Hydrocarbon Resources,” IIASA, WP-96-26, May 1996. 


\section{Appendix A}

Appendix A shows a procedure to enter data and run Schlumberger Eclipse software which was used to model the tight gas formation in this study. A coal bed methane template was used to enter tight gas formation for all cases.

Figure A-1 shows the Schlumberger Eclipse software landscape or main window through which when we hit Eclipse button on the top left corner we can create a new project of work

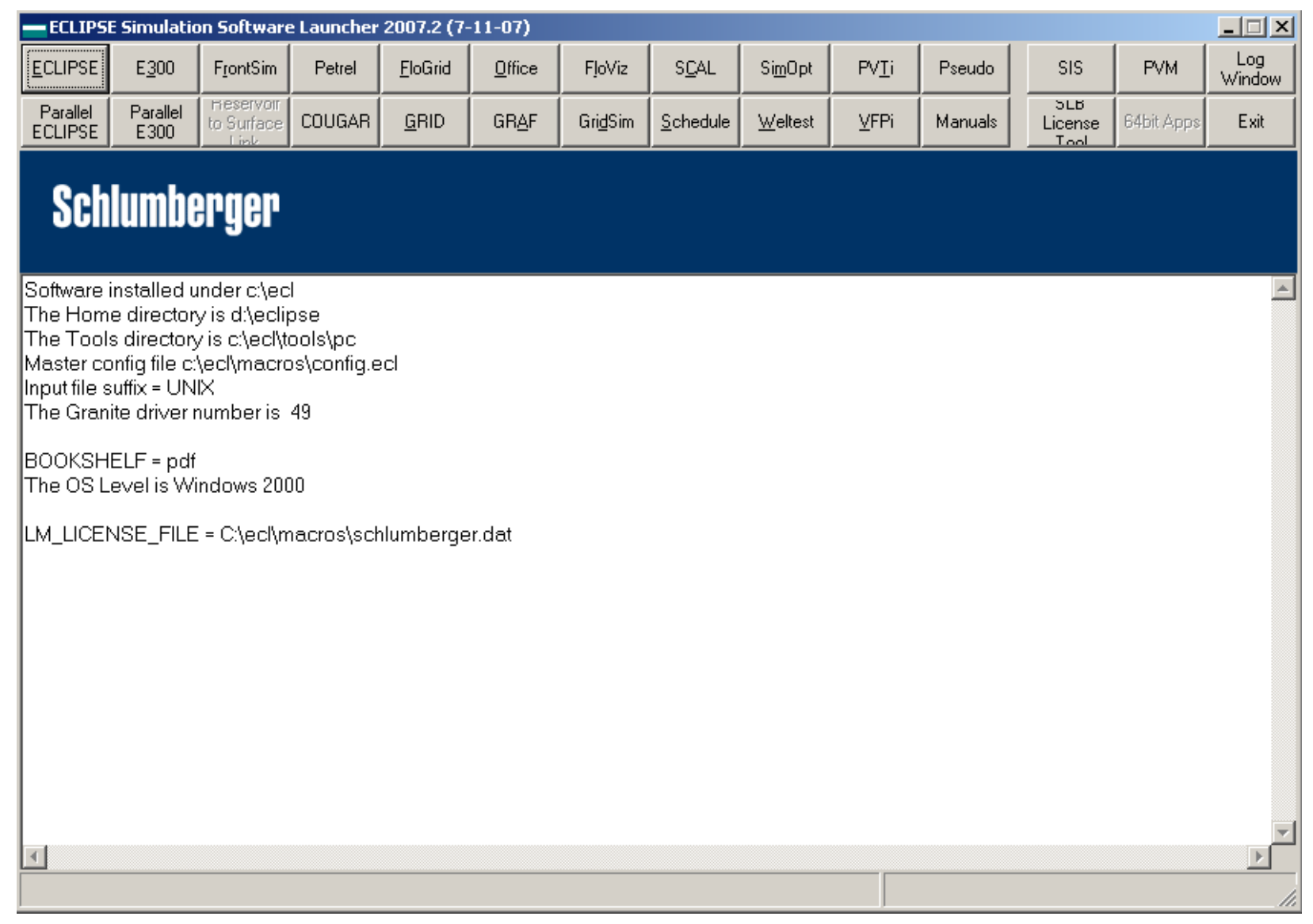

Figure A- 1 Schlumberger's Eclipse software main window 
After creating work file and saving it as shown in Figure A-2 below, the next step will be entering data into the software as shown in Figure A-3.

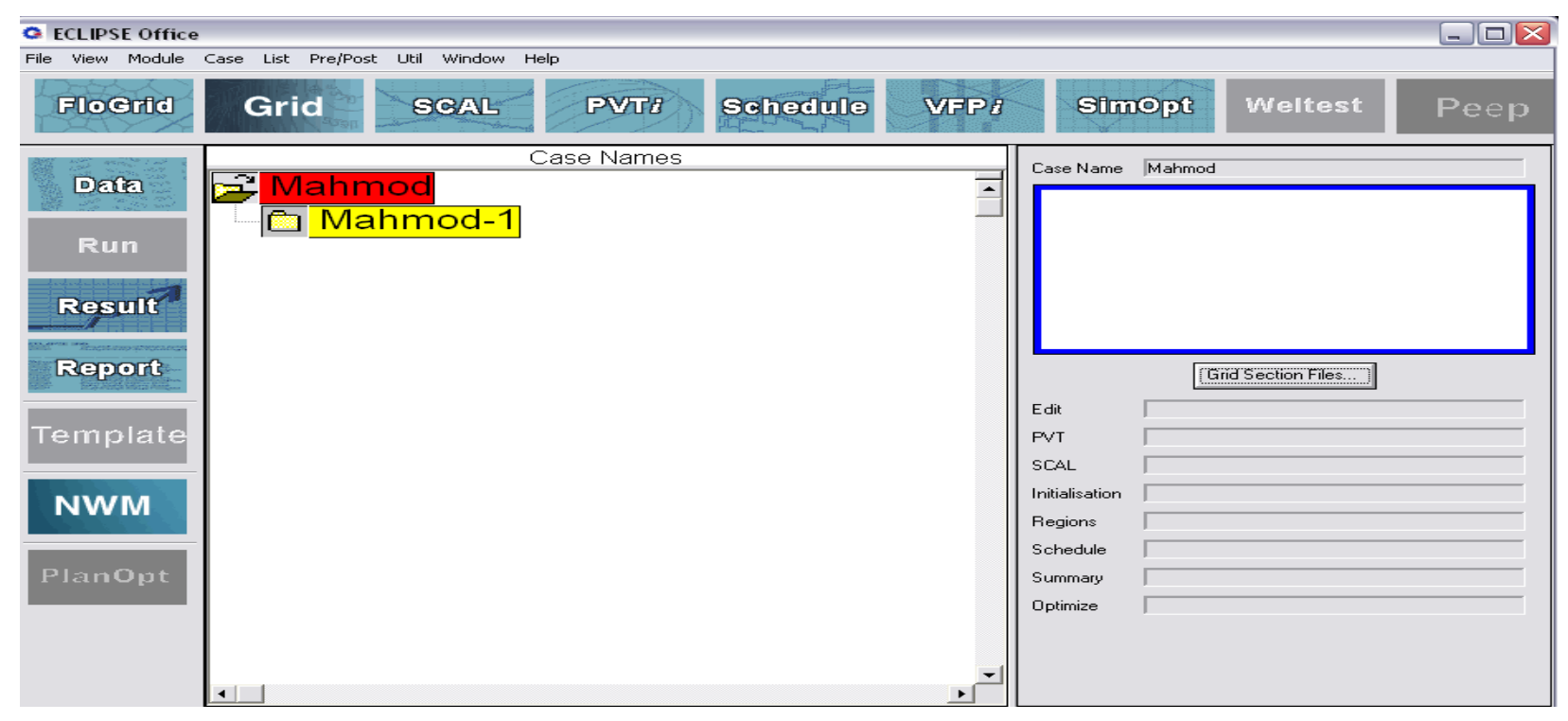

Figure A- 2 creating file work and saving work in it

Figure A-3 shows simulation model definition which includes simulation length and reporting of output production data. On the left hand side, a workflow tree appears.

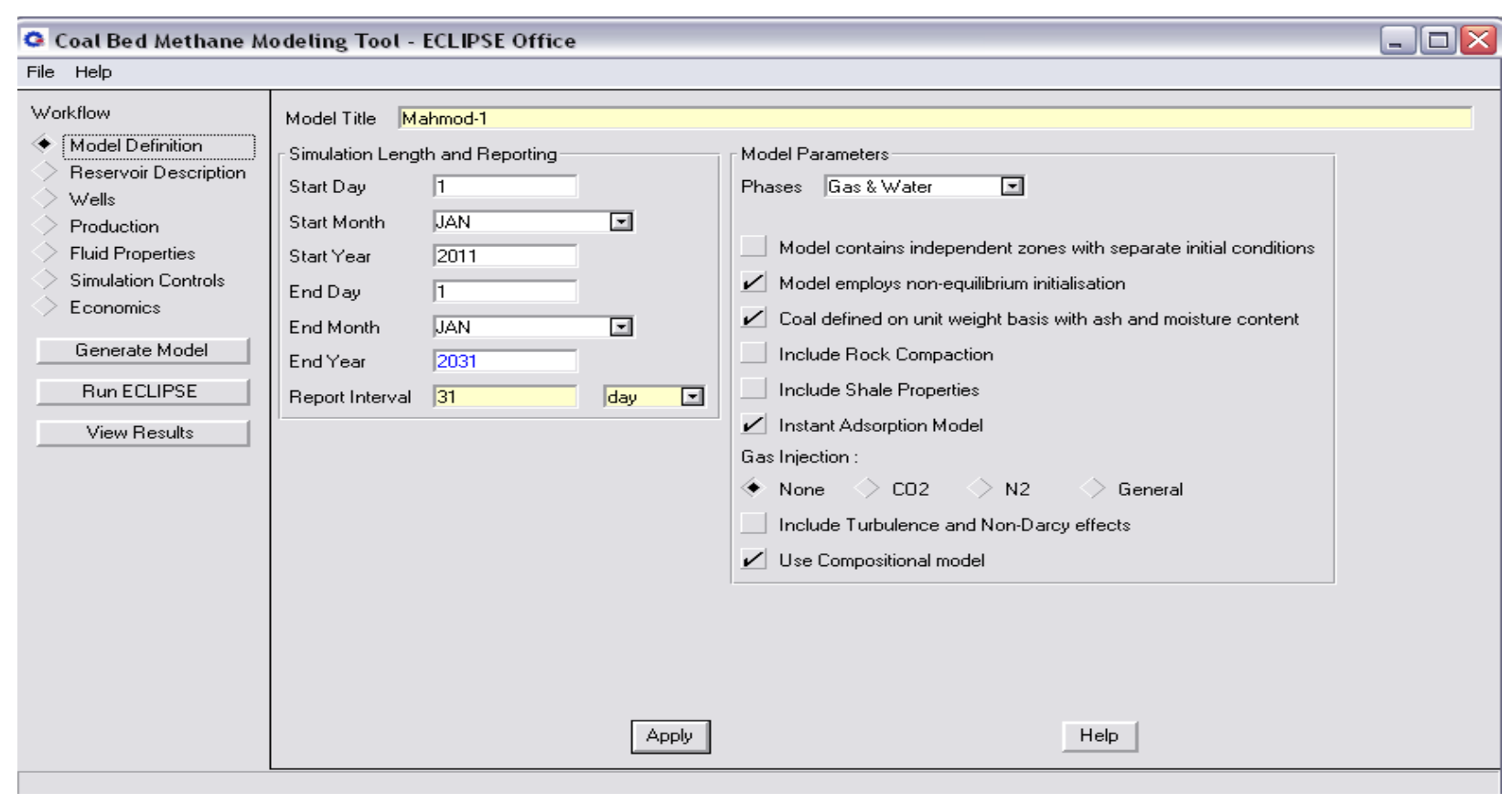

Figure A- 3 window shows simulation run period for gas production and main model options 
Four layers have been created with $40 \mathrm{ft}$ thickness each and $120 \mathrm{ft}$ thickness total. Figure A-4 shows reservoir description window with five taps among which highlighted tap is Layers option.

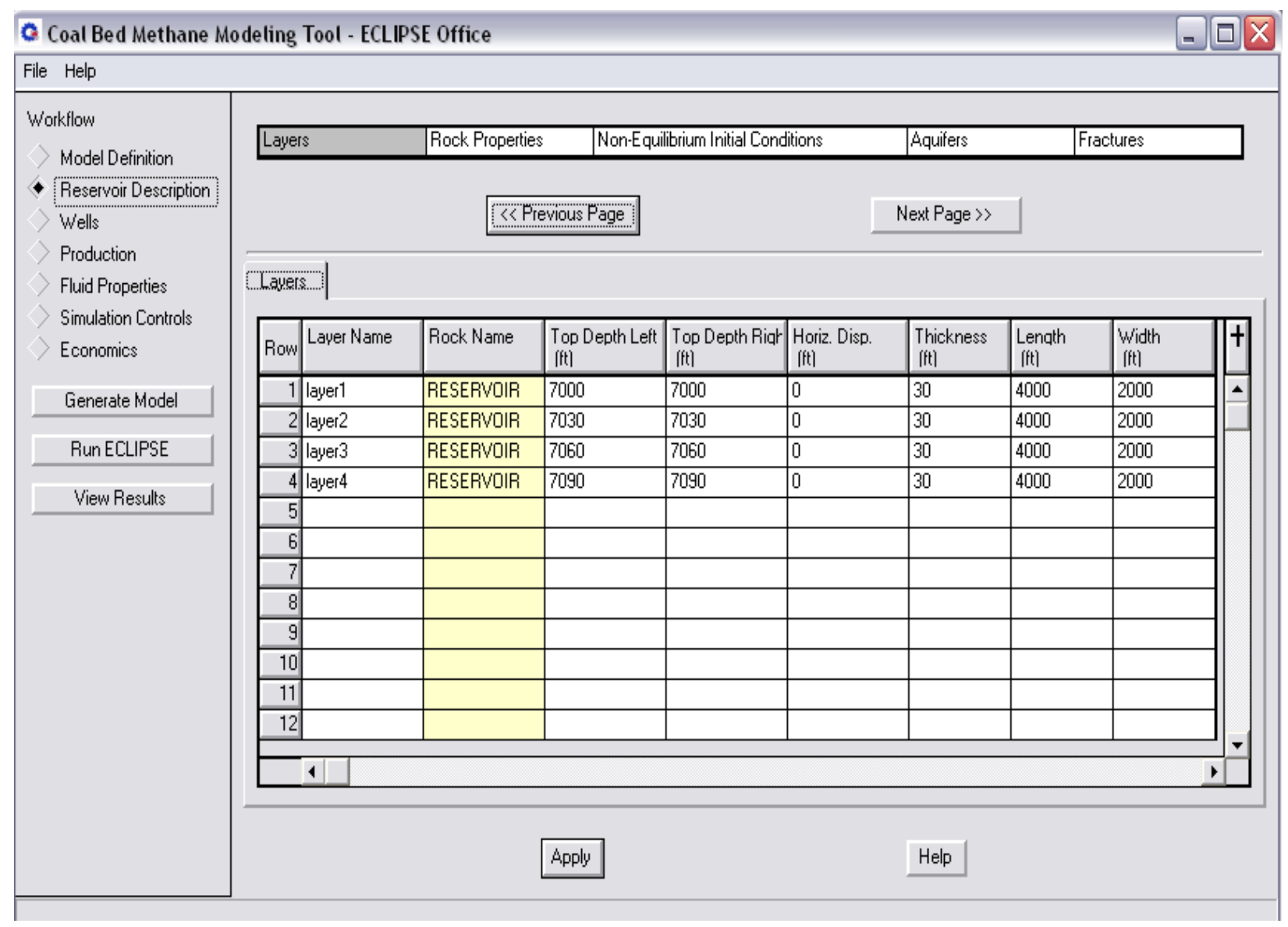

Figure A- 4 reservoir description window (Layers option)

Next tap in the reservoir description was reservoir rock properties data entry as shown below in figure A-5.Permeability in $\mathrm{x}, \mathrm{y}$ and $\mathrm{z}$ direction plus porosity and other data were specified and appointed in this tap. 


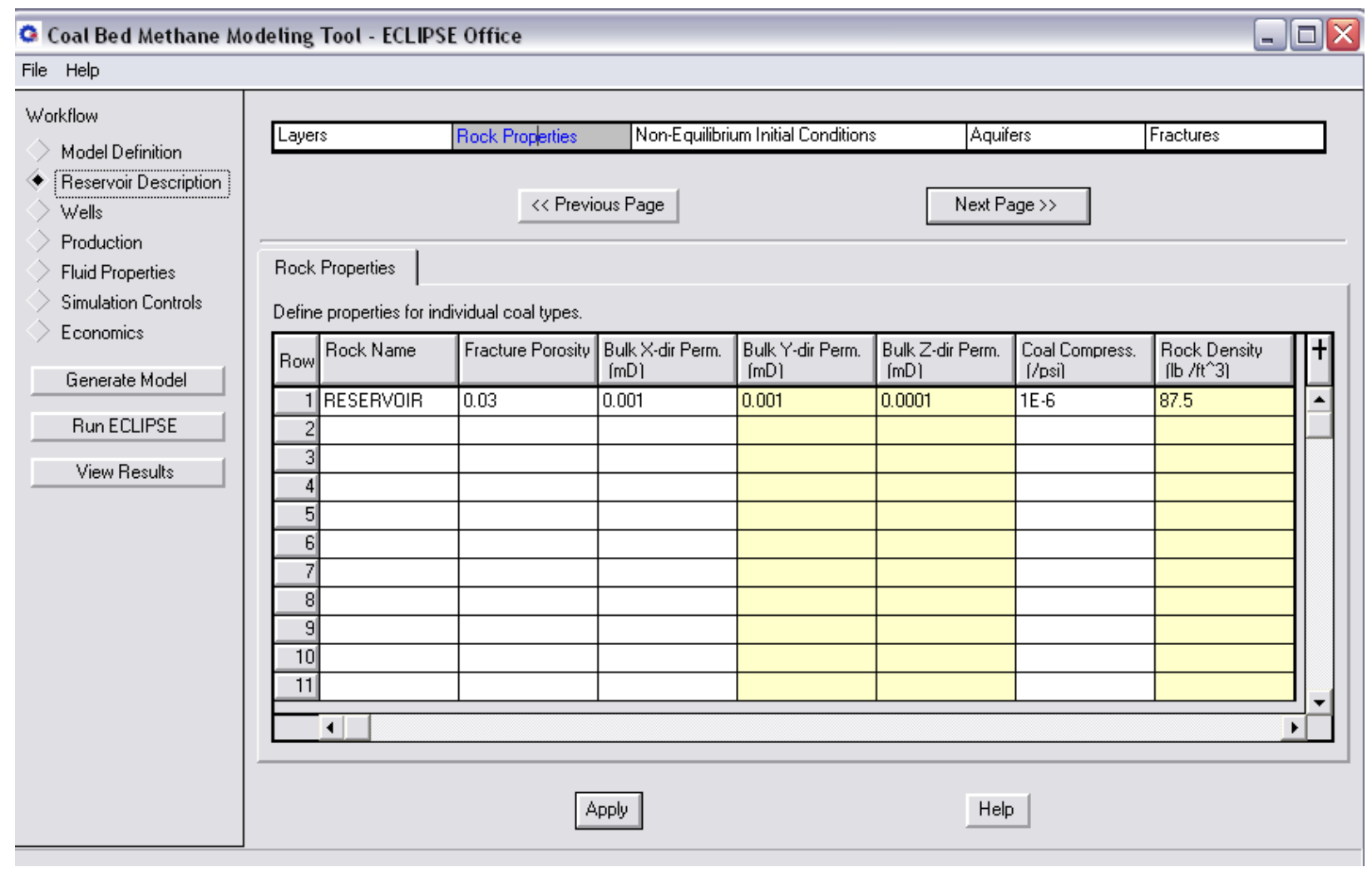

Figure A- 5 rock properties screen

Figure A-6 shows highlighted tap of non-equilibrium initial conditions which includes as shown in the screen below; initial reservoir pressure and water saturation.

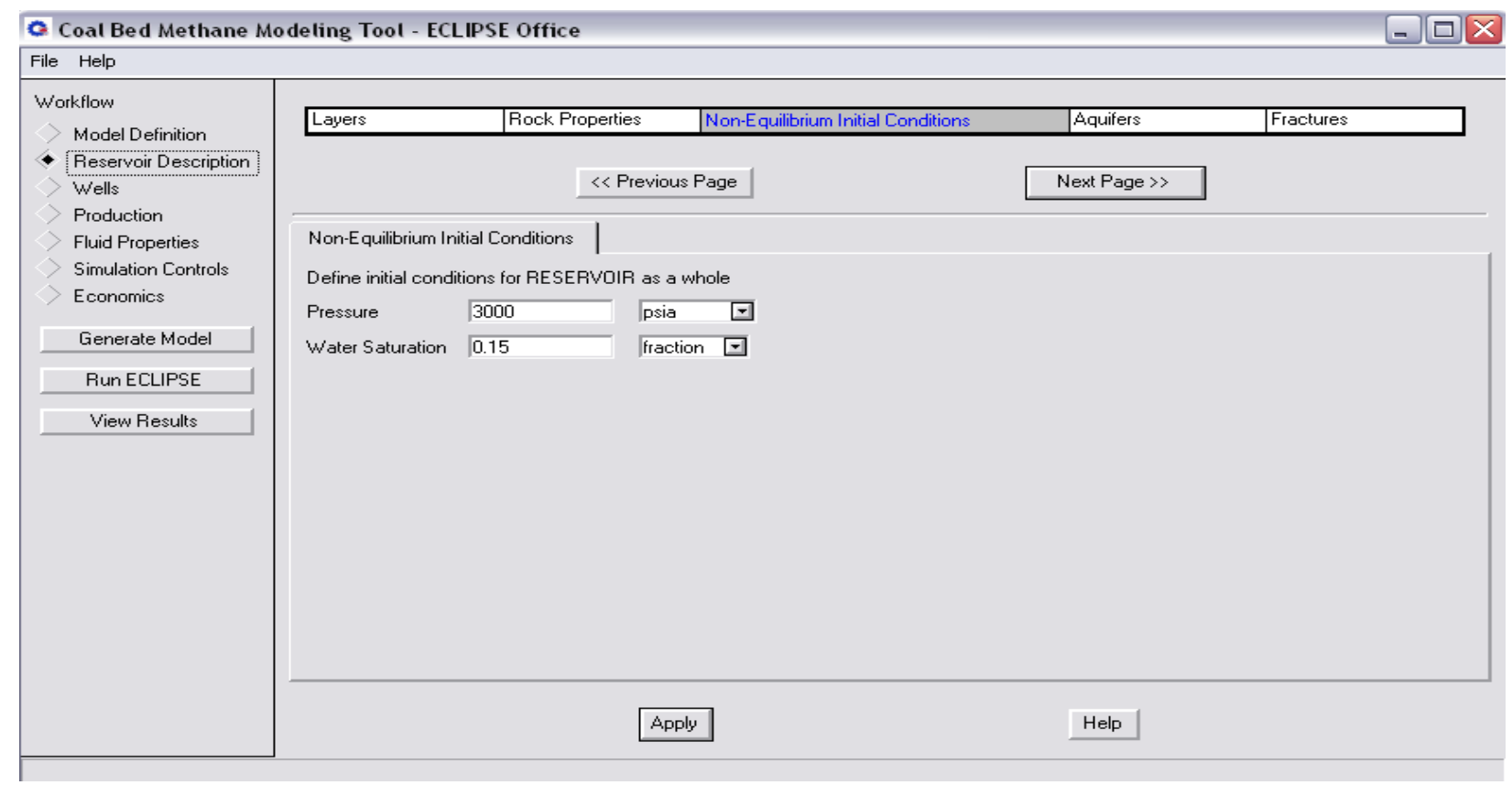

Figure A- 6 non-equilibrium conditions screen 
Figure A-7 shows the fractures tab for reservoir description. For this example a threestage fracture is shown. Each fracture withhalf length of $300 \mathrm{ft}$ and other properties were identical between fractures. These multiply fractures are perpendicular to wellbore of horizontal lateral part.

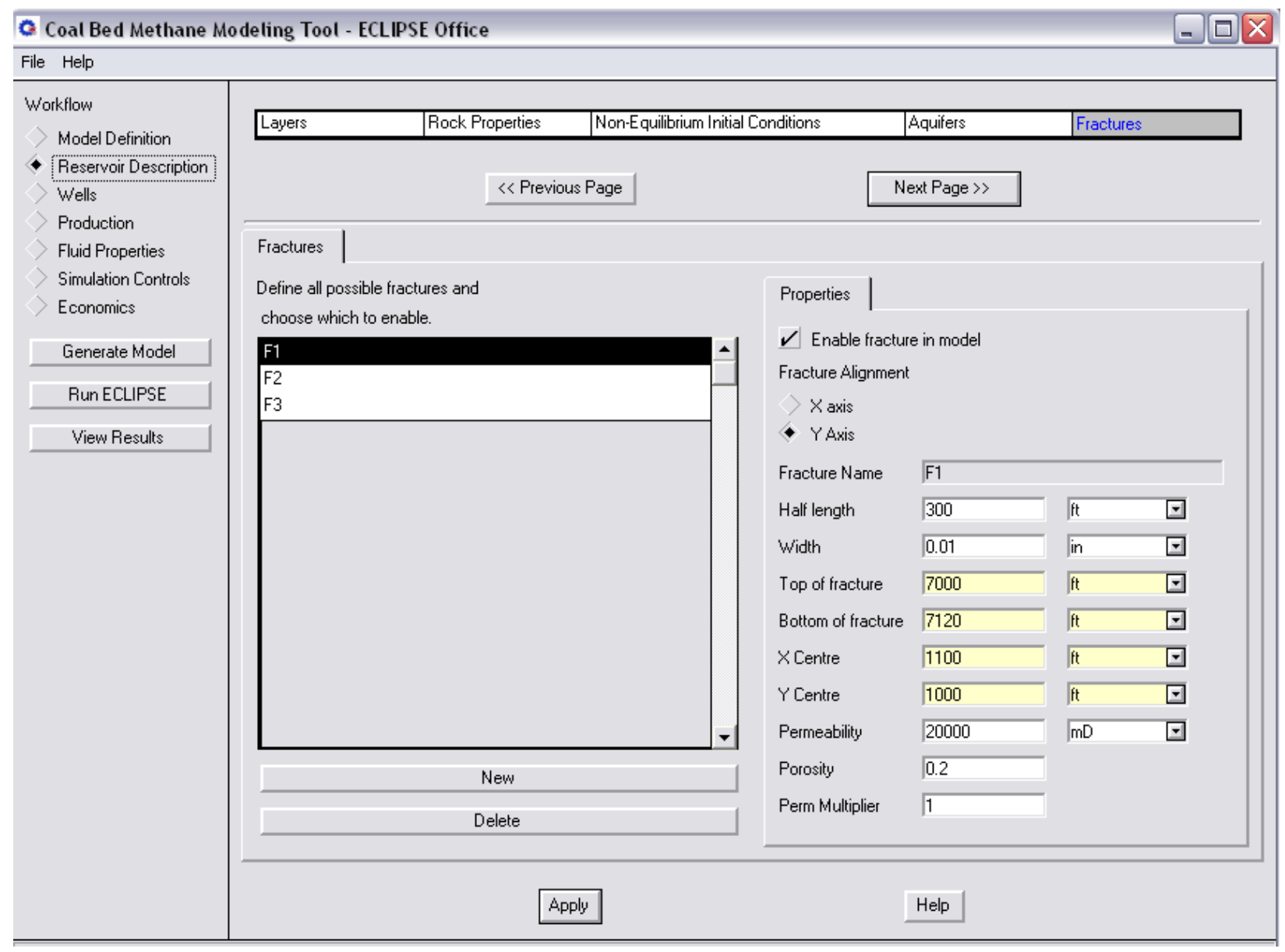

Figure A- 7 shows fractures screen 
Figure A-8 shows the wells section of the workflow where vertical and horizontal wells can be added to the reservoir. The snap shot below explains the depth of vertical portion of the well up to the reservoir.

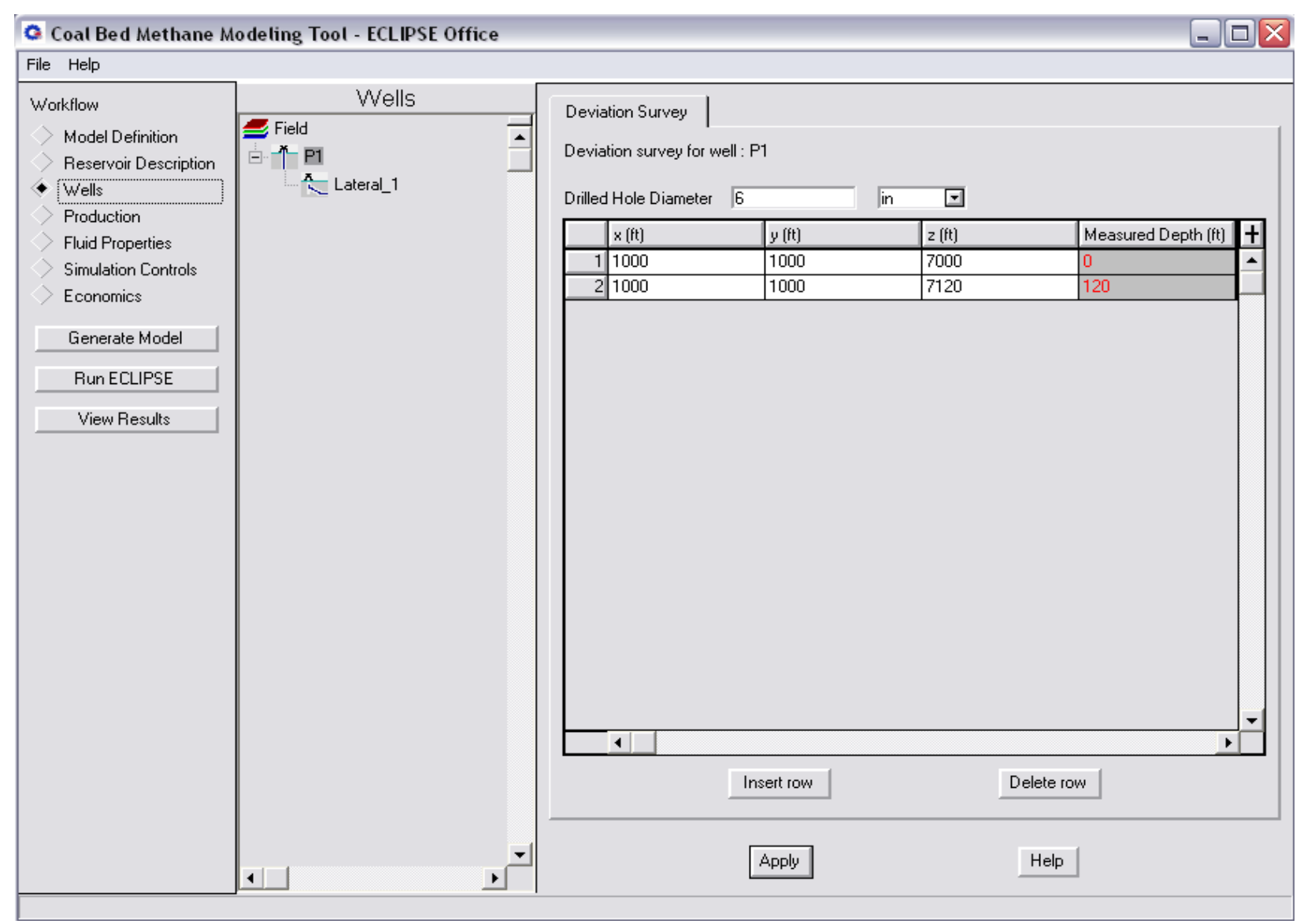

Figure A- 8 shows wells section of the workflow

Figure A-9 still in well section window but shows how to create lateral portion in the well, which in this case extends up to $3000 \mathrm{ft}$ across the $4000 \mathrm{ft}$ reservoir length. 


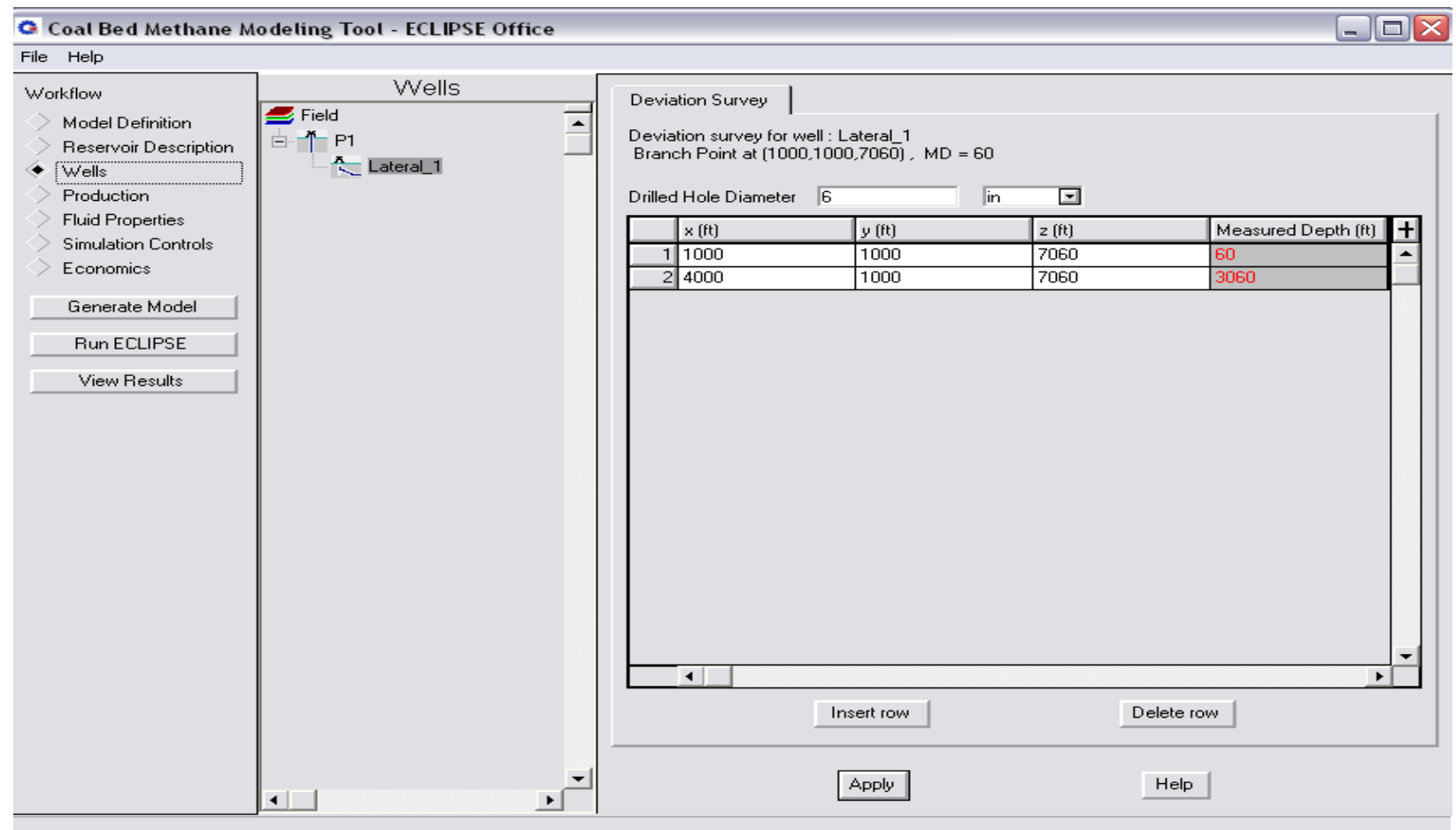

Figure A- 9 shows lateral section creation screen

Figure A-10 shows the production section of workflow. Once the well is defined different types of events can be selected, production is one of the events that needs to be added. Once production is added, well controls can be set.

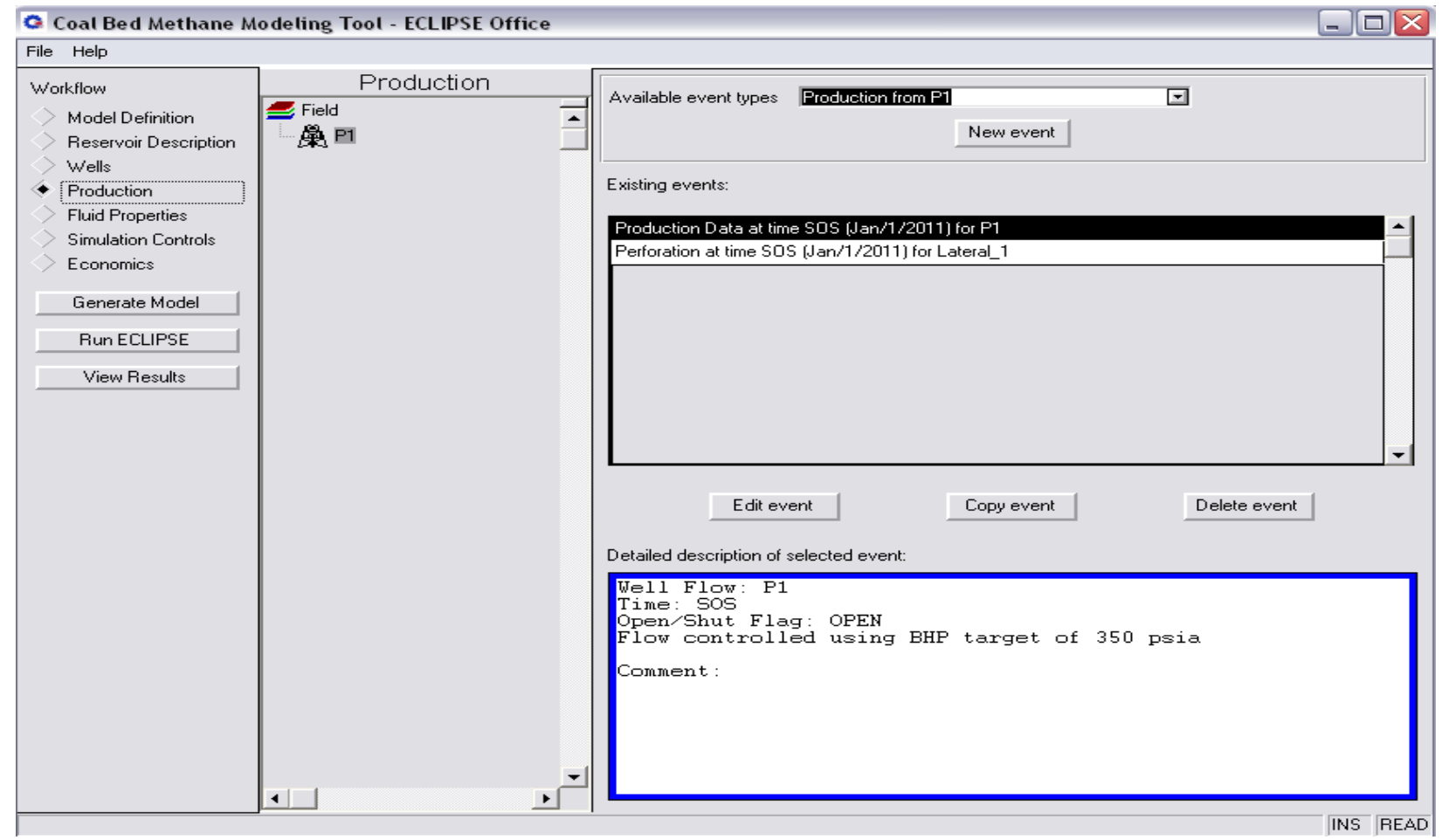

Figure A- 10 shows production section of workflow screen 
Figure A-11 shows workflow section of fluid properties such as standard pressure, standard temperature and reservoir temperature. Also, gas components percentage can be seen.

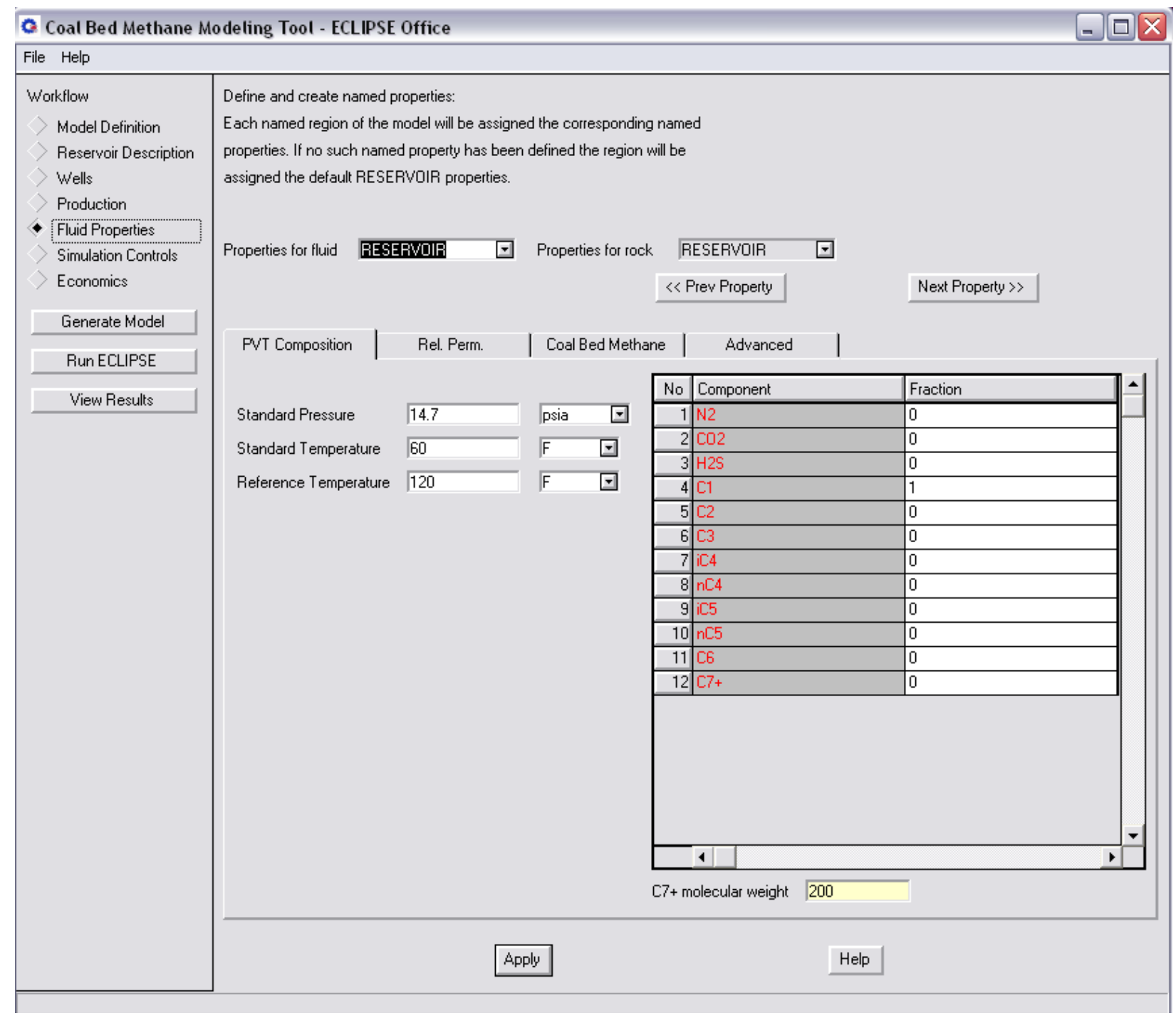

Figure A- 11 fluid properties screen 
Since coal bed methane template has been used, its properties such as Langmuir pressure, Langmuir concentration and sorption time has to be defined and are shown in Figure A-12 below.

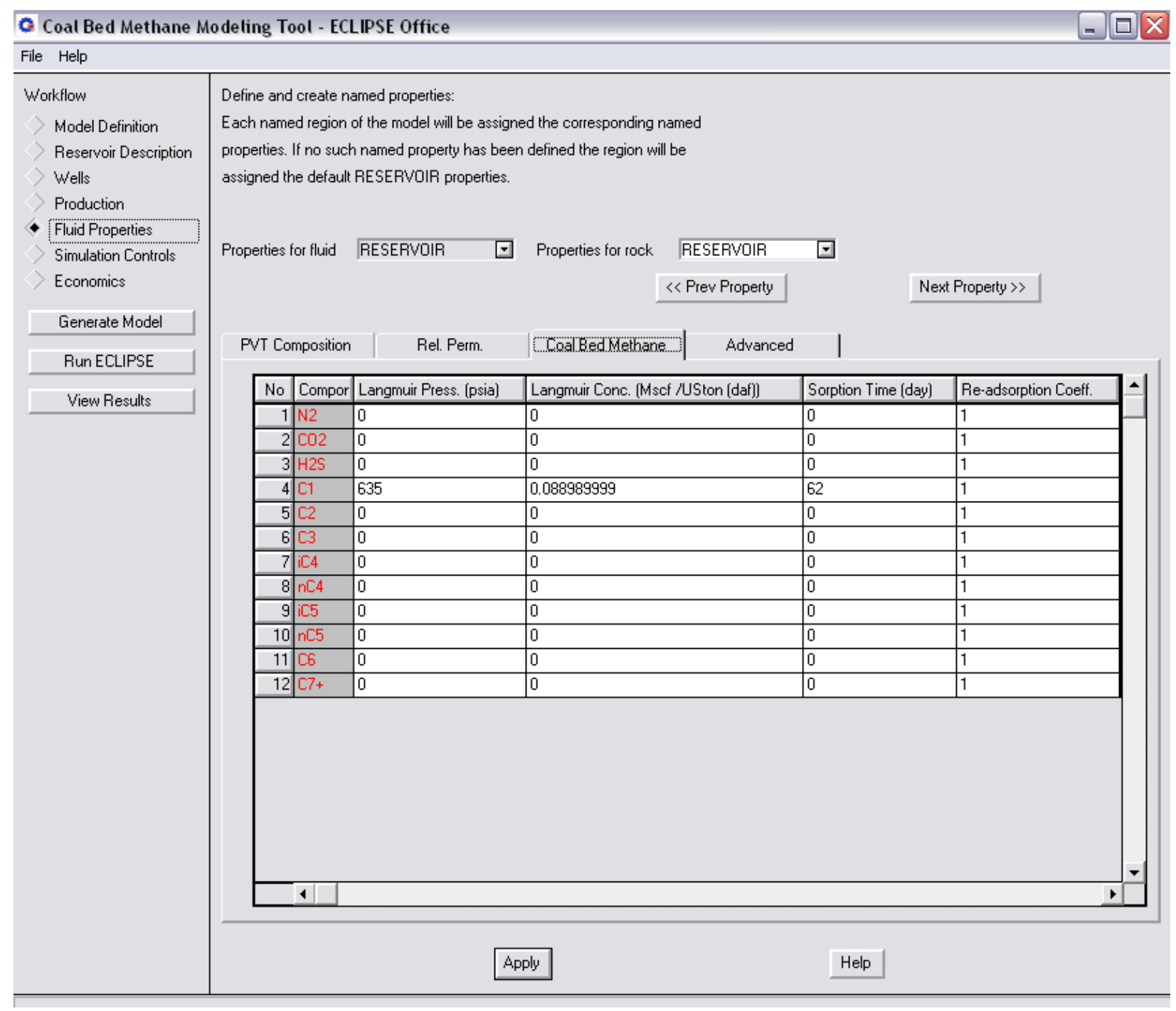

Figure A- 12 coal bed Methane properties screen 
Figure A-13 shows workflow section of simulation controls which includes reservoir grids size and they are adoptable upon desire of grid size of the reservoir because this option controls the speed of completion of the entire run. the larger grid size, the faster simulation run is done .

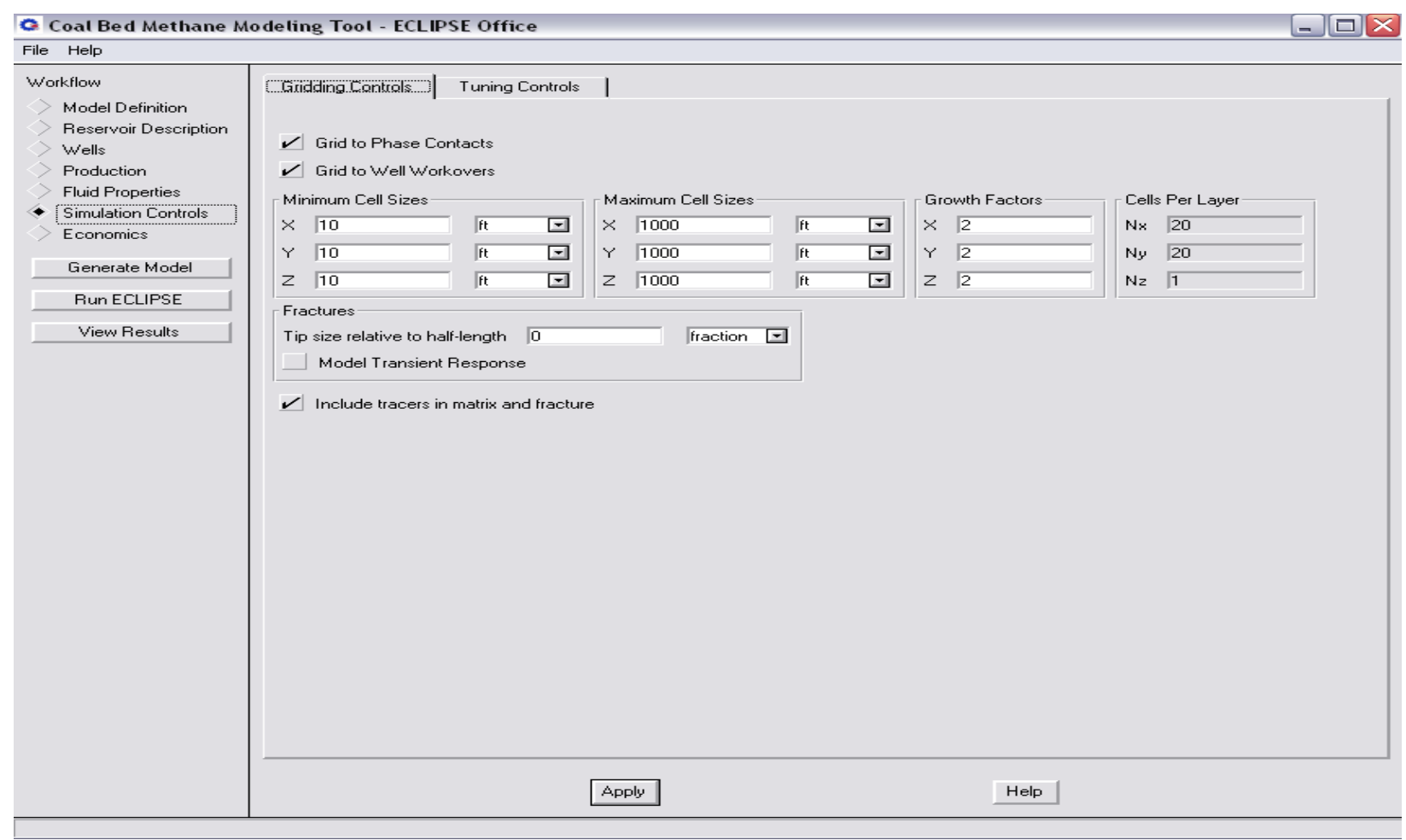

Figure A- 13 simulation controls screen

The workflow is followed by generalizing the model with proper specifications. FigureA14 shows the generated model for the $3000 \mathrm{ft}$ horizontal well with three fracture treatments of $300 \mathrm{ft}$ half length just as an example. The wellbore and generated fractures are shown as solid lines. The three lines in y direction are fractures whereas the central white line in $\mathrm{x}$ direction is the well bore. The heel of the well bore is marked by $\mathrm{P} 1$ and the too is all the way in $\mathrm{x}$ direction up to the tip of the reservoir. Figure A-15 shows the generated model of effective longitudinal 
fracture as an example. The red line in the center is the created longitudinal fracture along the lateral parts of the well I the $\mathrm{x}$ axis direction.

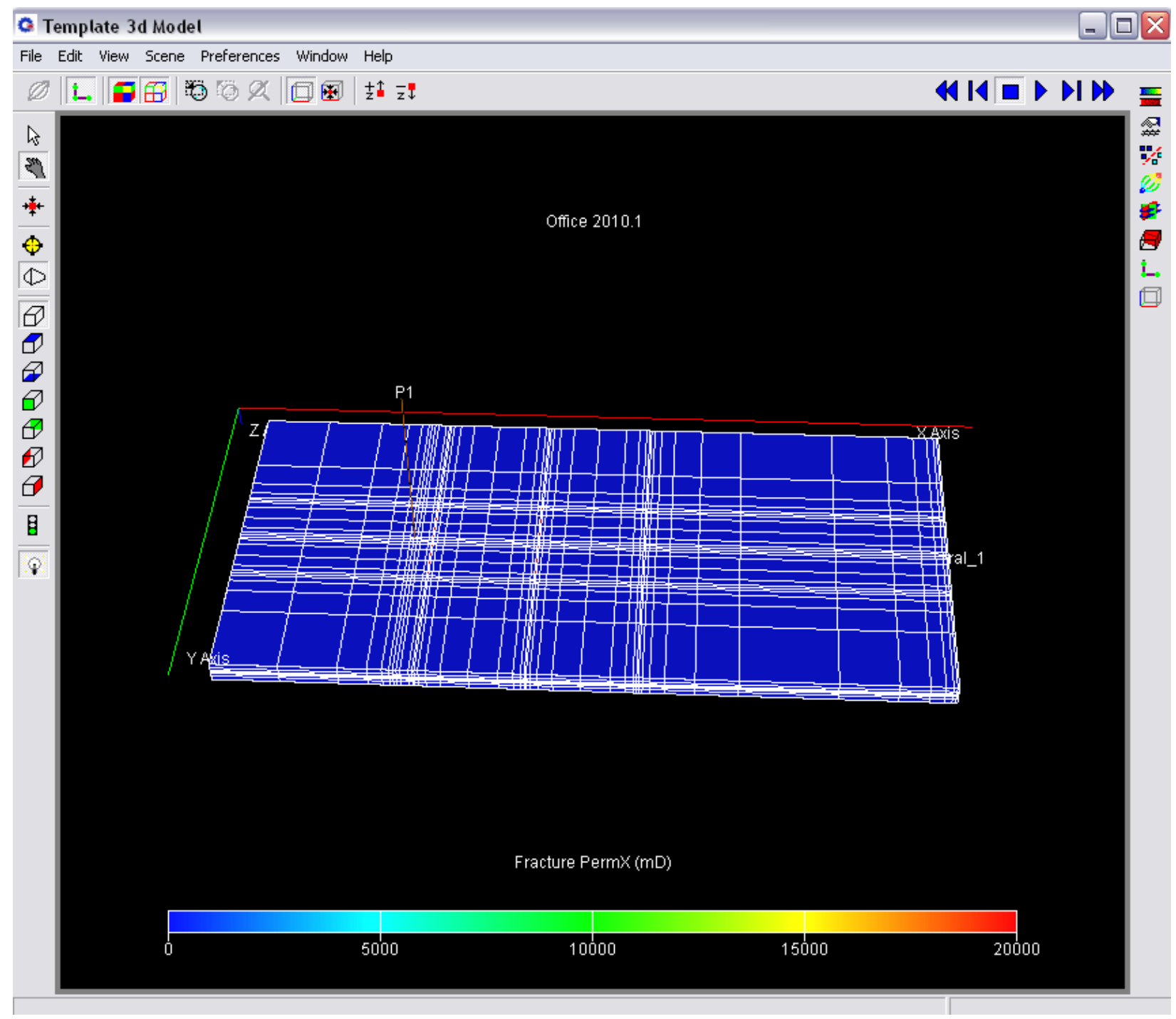

Figure A- 14 generated model of horizontal well with three multiply fractures 


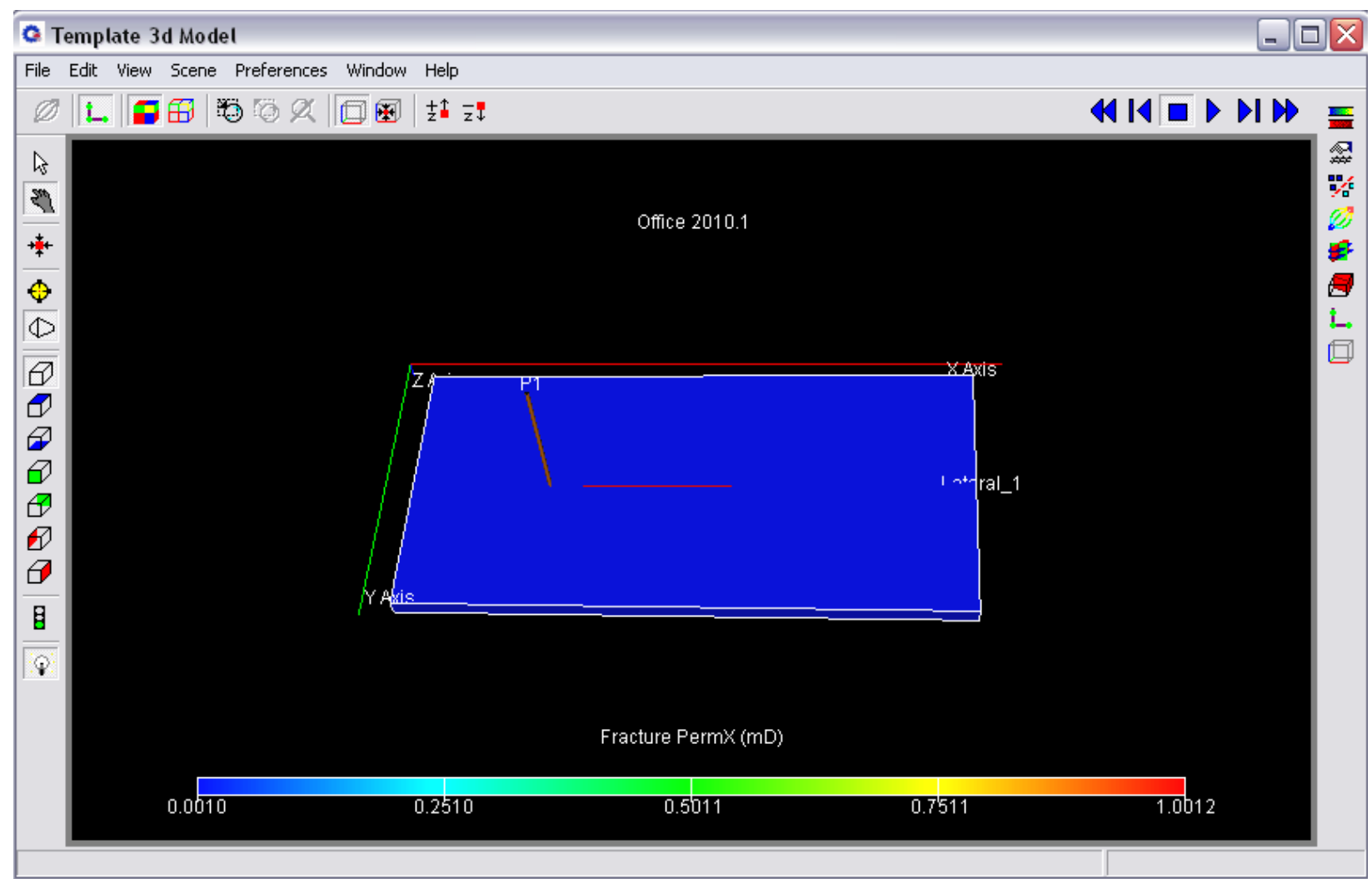

Figure A- 15 generated model in case of effective longitudinal fracture

Figure A-16 shows the simulation in the run, when the simulation calculates the values to give out the final results.

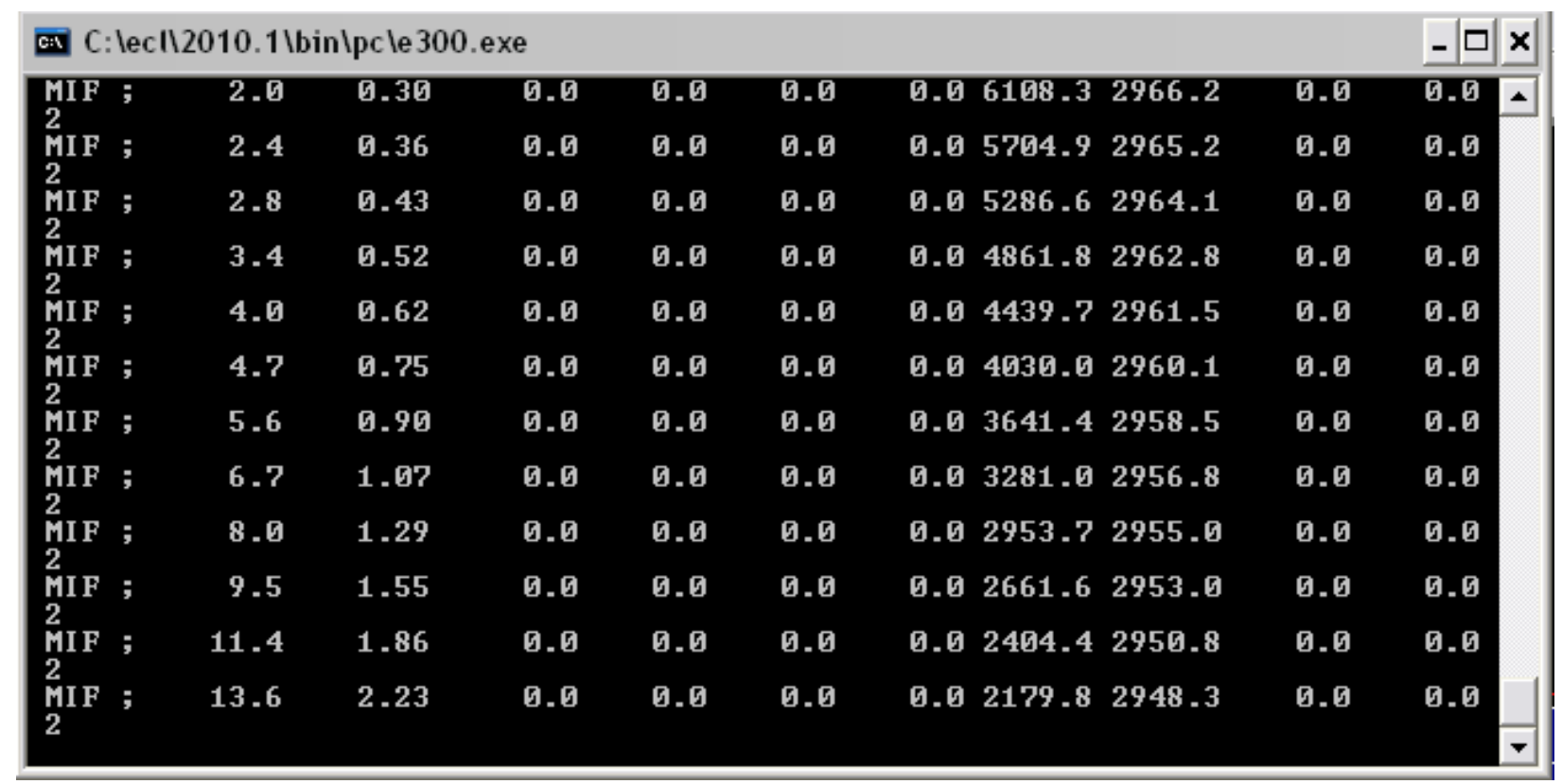

Figure A- 16 simulation in the run screen 
When the run is completed, a Display window will appear as shown below in figure A-17 below. White and yellow comments mean that everything is correct an acceptable even with some warnings but if red comments appear in the window, then a mistake will prevent a complete run to give good results

\begin{tabular}{|c|c|c|c|c|c|c|}
\hline \multicolumn{6}{|c|}{ - Messages Table for MAHMOD-1_E300.MSG } & $\square \square x$ \\
\hline \begin{tabular}{|l|l|} 
Row & Type \\
\end{tabular} & Date & Time & Description & & & $\Delta$ \\
\hline \begin{tabular}{l|l|}
1 & Warning \\
\end{tabular} & $0 / 0 / 0$ & 0.000 & SCFDIMS IGNORED AS NO FRACTURES DEFINED & & & \\
\hline 2 Message & $1 / 1 / 2011$ & 0.000 & CHECKING FOR LICENSES & & & \\
\hline 3 Message & $1 / 1 / 2011$ & 0.000 & CHECKING FOR LICENSES & & & \\
\hline \begin{tabular}{l|l|l|}
4 & Message \\
\end{tabular} & $1 / 1 / 2011$ & 0.000 & CHECKING FOR LICENSES & & & \\
\hline \begin{tabular}{l|l|}
5 & Message \\
\end{tabular} & $1 / 1 / 2011$ & 0.000 & ECLIPSE LICENSE EXPIRES 18-FEB-2013 & & & \\
\hline 6 Message & $1 / 1 / 2011$ & 0.000 & READING FROM INCLUDE FILE MAHMOD-1_GGO.INC & & & \\
\hline \begin{tabular}{l|l|}
7 & Warning \\
\end{tabular} & $1 / 1 / 2011$ & 0.000 & KEYWORD NODPPM SHOULD ONLY OCCUR ONCE & & & \\
\hline \begin{tabular}{l|l|}
8 & Warning \\
\end{tabular} & $1 / 1 / 2011$ & 0.000 & KEYWORD DPGRID SHOULD ONLY OCCUR ONCE & & & \\
\hline 9 Message & $1 / 1 / 2011$ & 0.000 & READING FROM INCLUDE FILE MAHMOD-1_GPRO.INC & & & \\
\hline 10 Message & $1 / 1 / 2011$ & 0.000 & PROCESSING GRID DATA & & & - \\
\hline 1 & & & & & & $\rightarrow$ \\
\hline$\checkmark$ Error & $\checkmark$ Mess & & Search in Description & & Find & \\
\hline$\checkmark$ Bugs & $\checkmark$ Comm & & & & & \\
\hline$\checkmark$ Warning & $\checkmark$ Proble & & & & & \\
\hline & & & Close & Open Current PRT File & & \\
\hline
\end{tabular}

Figure A- 17 display window of comments

Figure A-18 shows results of the model. As seen below, total gas production of the model with time is in display

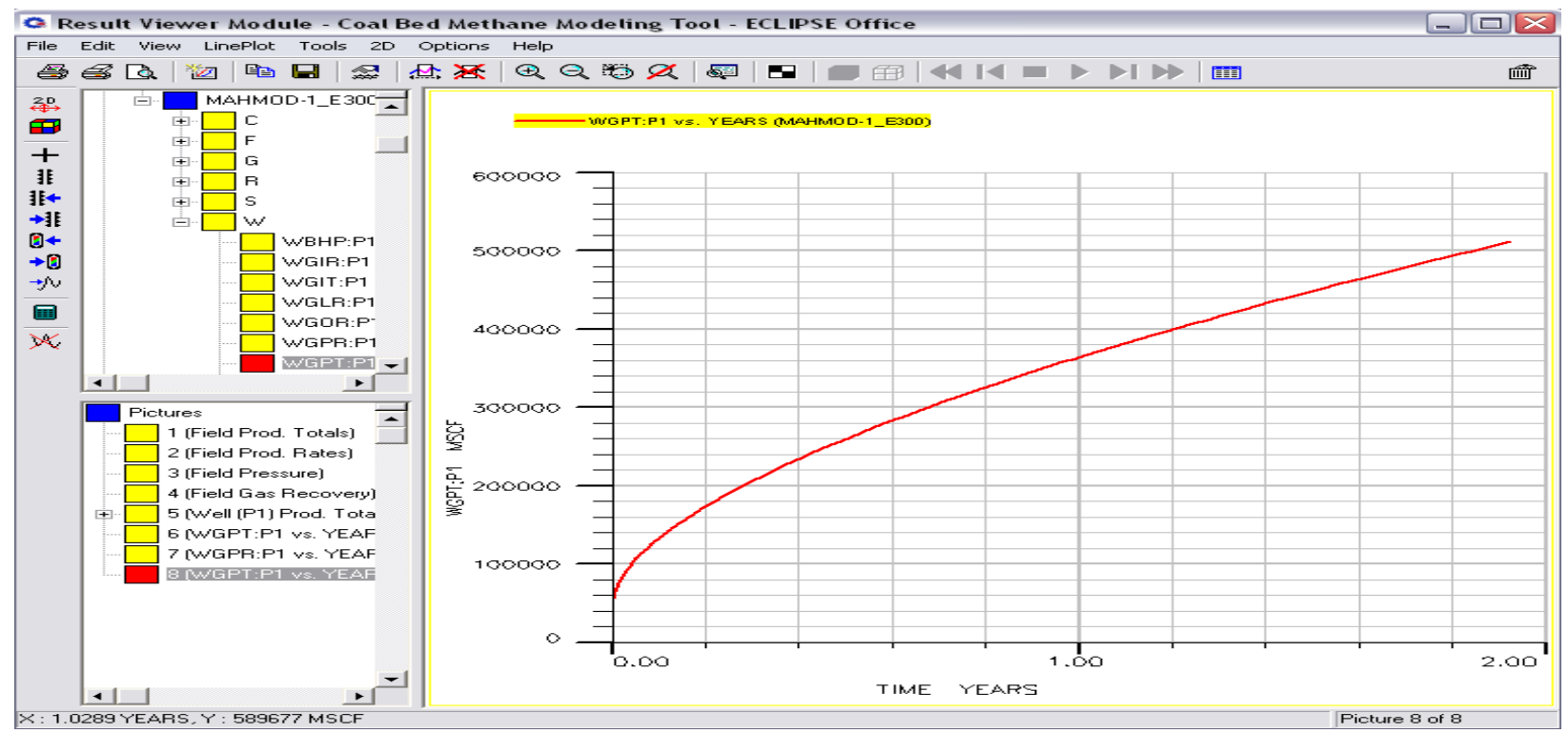

Figure A- 18 total gas production display screen 
Field pressure drop is displayed in figure A-19 below. An example of field pressure drop after 20 years of gas production is shown in figure A-19.On the left hand side of the window, results flow tree is shown.

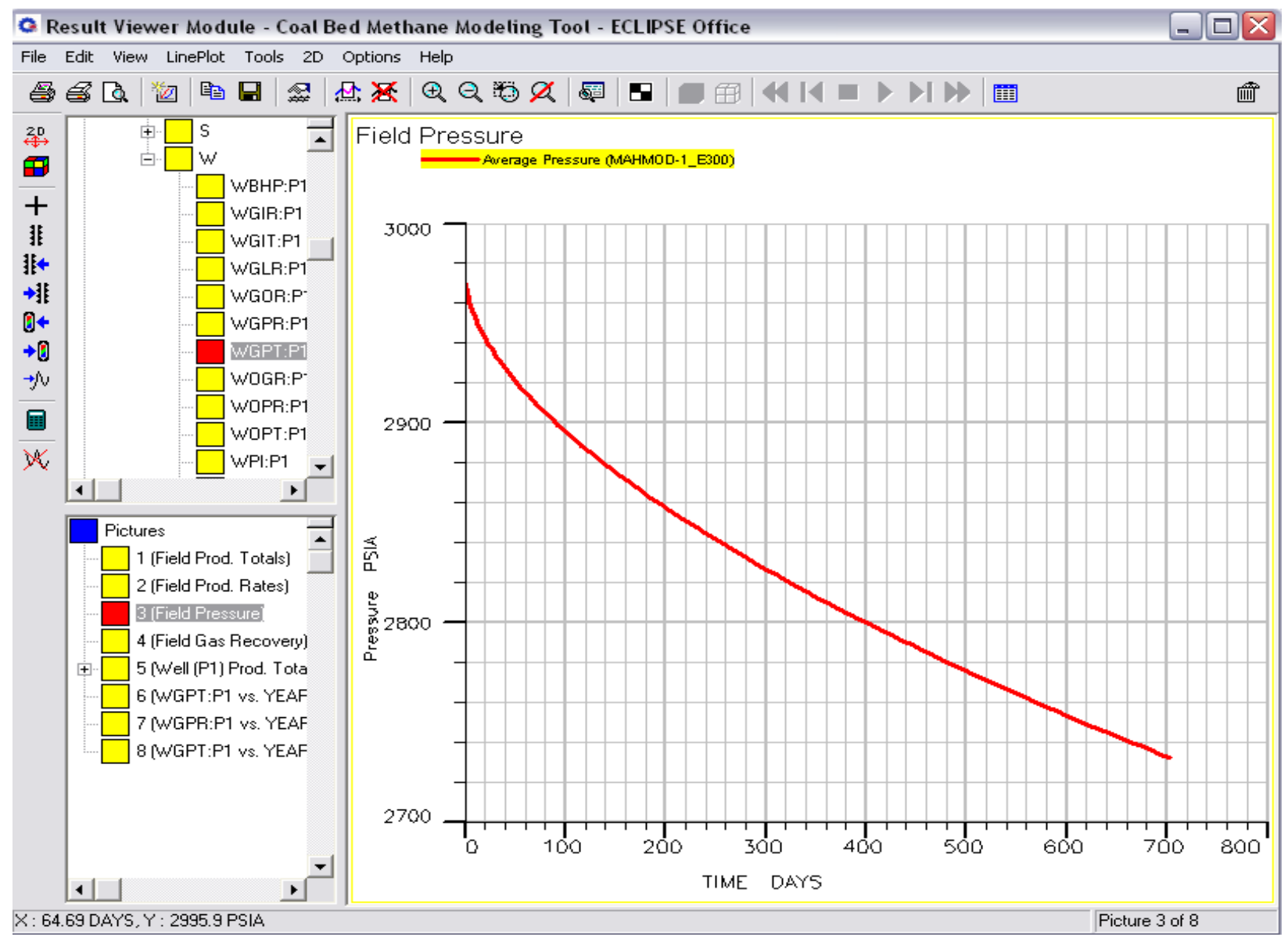

Figure A- 19 display screen of field pressure 
Figure A-20 shows pressure drop around three multiply fractures after 20 years of gas production. The blue lines are the fractures with the least pressure value whereas the red area represents the distribution of the gas pressure in the reservoir around the fractures.

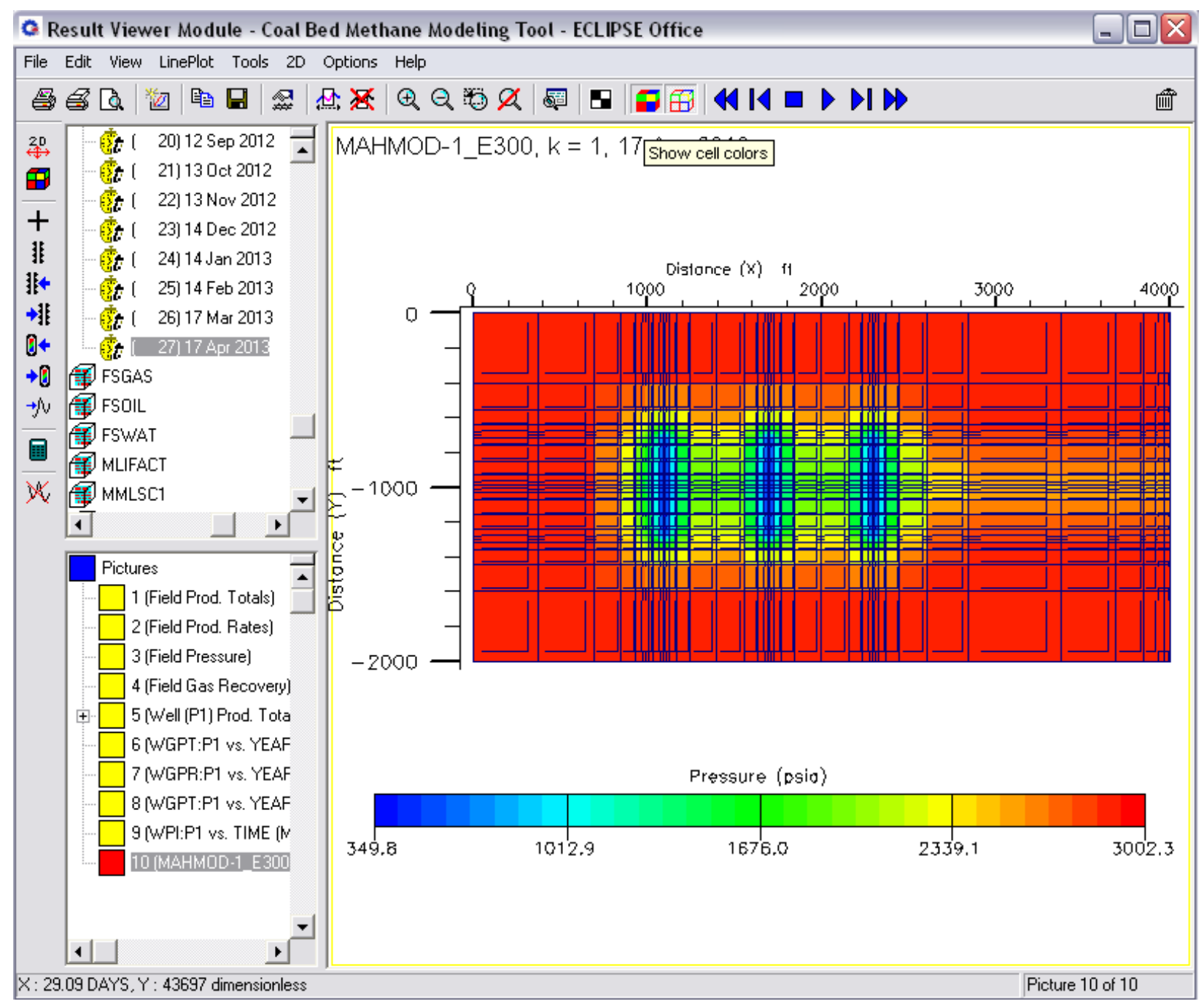

Figure A- 20 shows pressure distribution in and around fractures after 20 years of gas production

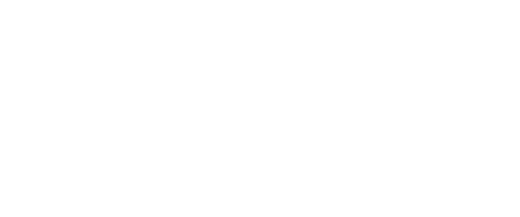

